\title{
Arbor
}

\section{De la trepanación a la cirugía virtual}

\section{Pedro García Barreno}

Arbor CLXXVII, 698 (Febrero 2004), 365-417 pp.

Para los que la historia de la Cirugía es la historia de las operaciones quirúrgicas, parece lógico que tras el descubrimiento de cráneos neolíticos trepanados se ubique sus orígenes en el periodo prehistórico (Figura 1). También, el estudio a finales del s. XIX y a comienzos del s. XX de tribus primitivas aun existentes, reveló prácticas de suturas de heridas y de inmovilización de miembros fracturados que se interpretaron como vestigios de una cirugía prehistórica. Hoy, se conocen fragmentos escritos que recogen pruebas de práctica quirúrgica en las civilizaciones arcaicas de Egipto y de Mesopotamia. La mayor parte de los conocimientos que se tienen de la medicina egipcia se han obtenido de papiros, en particular de dos: el Edwin Smith y el Ebers. El primero, base de los tratamientos quirúrgicos del antiguo Egipto, es un manuscrito de 17 páginas en el recto y cinco en el reverso que fue puesto a la venta por Mustafa Agha en 1862 y adquirido por un aventurero norteamericano, Edwin Smith. A su muerte, su hija lo donó, en 1906, a la Sociedad de Historia de Nueva York. Actualmente se encuentra en la Academia de Ciencias de aquella ciudad. En la primera época dinástica la cirugía estaba limitada a pequeñas operaciones, curación de heridas y contusiones, entablillado de fracturas $\mathrm{y}$, posiblemente, la exéresis de pequeñas tumoraciones. $\mathrm{El}$ papiro Edwin Smith es el tratado de cirugía más antiguo conocido; incompleto, su primera traducción fue realizada por Breasted en 1930, y consta, en su mayor parte, del Libro sobre las heridas. Por su parte, el papiro Ebers es un texto completo; un compendio de medicina en un rollo de 20 metros. Su primera traducción, hecha por Joachim, es de 1890 . Ambos papiros fueron escritos hacia el 1600 a. C., al final del II Período Intermedio o durante la XVIII dinastía; el papiro Ebers algo después que 


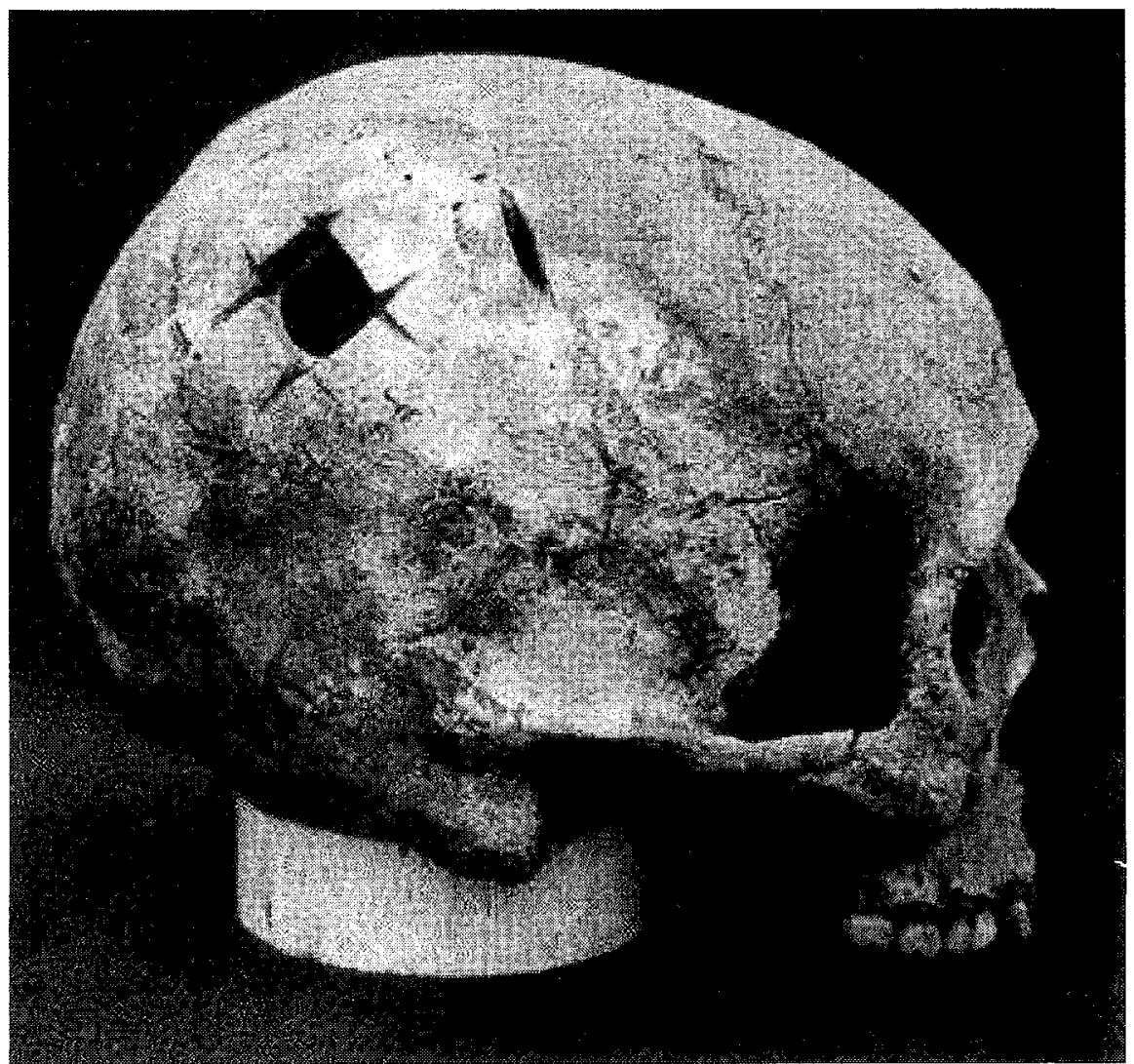

Figura 1. Cráneo trepanado perteneciente a la cultura Paracas (700 a. C. - 1100), caracterizada por su desarrollo técnico y cultural. Destacó por la calidad de sus textiles y la habilidad para la trepanación. En el Museo Nacional de Arqueología, Antropología e Historia, Perú.

el Smith, y probablemente proceden de una misma tumba en Tebas. Estos papiros mostraron una base empírico-racional de la medicina egipcia que, como la mesopotámica, había sido considerada de carácter mágicoreligioso por los historiadores. Por su parte, las inscripciones cuneiformes de la estela de Hammurabi -rey de Babilonia, c 1792 a. C. a 1759 a. C.- recogen normas relativas a las operaciones manuales de los médicos en Mesopotamia.

Rastrear la tradición médica Occidental hasta la Grecia clásica es fácil. Generaciones de médicos y de cirujanos han proclamado su heredad intelectual de Hipócrates de Cos y su adhesión a una práctica médica basada sobre principios éticos, racionales y de independencia de juicio ba- 


\section{De la trepanación a la cirugía virtual}

sado en la experiencia y el aprendizaje. La superstición no tiene cabida, y las creencias populares y el dogmatismo religioso están excluidas. La Medicina, como la Filosofía o el Teatro, es parte el milagro griego. Sin embargo, una coexistencia relativamente amigable entre medicina y religión es uno de los aspectos del pluralismo de la medicina griega. Los «sanadores»-hombres y mujeres- competían con expendedores de brebajes, exorcistas, parteras, curanderos, litotomistas y cirujanos, por los pacientes. Incluso en el Corpus Hipocrático -escrito entre 420 y 370 a. C., y compilado en Alejandría hacia 280 a. C.- se encuentran marcadas diferencias teóricas entre los diferentes tratados escritos, indudablemente, por diferentes autores. El Corpus Hipocraticum (siglos V - III a. C.) y otros trabajos helenísticos posteriores tratan la cirugía y la medicina en conjunto, lo que es consistente con que los profesionales peripatéticos poseían habilidades médicas y quirúrgicas. El Corpus Hipocrático contiene material netamente quirúrgico: un tratado sobre las heridas (De Ulceribus) y otro sobre lesiones de la cabeza (De Capitis Vulneribus) en el que se incluyen indicaciones para la trepanación. En el tratamiento hipocrático de las heridas se encuentra la teoría -una de las que mantuvieron su influencia indiscutida durante siglos- de que cierto grado de supuración es esencial para la cura de las lesiones.

Para los hipocráticos la medicina es un quehacer eminentemente ético. Juramento (Hórkos) es el escrito más breve, pero también uno de los más interesantes del Corpus Hippocraticum y de los más estudiados. Algunos autores vieron en Juramento la expresión de constantes éticas de la humanidad y que reflejarían principios atemporales, cuyo reconocimiento lo exige la propia decencia humana o las esenciales responsabilidades inherentes a la profesión de médico. Hipócrates y su escuela no se limitaron a otorgar a la medicina el estatuto teórico de ciencia, sino que llegaron a determinar con una lucidez realmente notable la dimensión ética del médico, el ethos o personalidad moral que lo debe caracterizar. Además del trasfondo social que se constata a través de la conducta que se explicita, el sentido del juramento se resume mediante la proposición que, en términos modernos, podría expresarse: médico, recuerda que el enfermo no es una cosa ni un medio, sino un fin, un valor y por tanto condúcete en coherencia con ello.

Los ocho libros de De Medicina, escritos en el siglo I por el enciclopedista romano Aulo Cornelio Celso (25 a. C. - 50), son una fuente indispensable de la medicina de la Grecia clásica. De Medicina fue uno de los primeros textos médicos impresos en 1478. Aunque la mayor parte del texto es mera transcripción de los hipocráticos, Celso amplia el campo quirúrgico, debiendo destacarse que realiza las amputaciones en zona de 
tejido sano; una actitud contraria a la de Hipócrates, quién practicaba la sección en tejido gangrenado.

En el s. II destacó el médico romano Galeno de Pérgamo (129-c. 200/216), en cuya prolífica obra -muy influida por Hipócrates- se discuten, con frecuencia, temas quirúrgicos; en especial en el Methodus $\mathrm{Me}$ dendi. De las heridas, Galeno escribió que es preferible la cicatrización por primera intención. El cierre de las heridas se conseguía mediante vendaje, sutura o la sujeción de los bordes mediante un pasador. La hemostasia se conseguía mediante la torsión del vaso o su ligadura con hilo o seda (esta última no fue mencionada por Hipócrates). Indicó la trepanación en las fracturas craneales con depresión del fragmento óseo, y en las heridas penetrantes abdominales señaló que el intestino grueso podía suturarse con éxito, el ileon en ocasiones y el yeyuno nunca. Sin embargo, la experiencia de Galeno como cirujano es materia de discusión. El contenido quirúrgico de su obra es menos importante para la historia de la cirugía que su sistema médico global y que incluyó la anatomía, fisiología, patología y terapéutica. El sistema galénico basado en el humoralismo estableció la ortodoxia de la medicina Occidental hasta el s. XVI, y mantuvo cierta relevancia hasta el s. XIX. Ello tuvo importantes consecuencias para la cirugía que, en su vertiente teórica, académica, explicó la patología quirúrgica - como la médica - en términos de desequilibrios humorales más que en las alteraciones locales que los cirujanos «prácticos» diagnosticaban y trataban. Desde un punto de vista práctico, las sangrías preconizadas por Galeno para la corrección de tales desequilibrios llegó a ser una medida terapéutica importante que, dado su carácter práctico fue dejada a los cirujanos, para quienes llegó a representar una parte muy importante de su trabajo.

La caída del Imperio Romano Occidental condujo a la destrucción de los vínculos comerciales europeos, al resurgimiento de la agricultura y al ocaso de las ciudades. Los trabajos «ilustrados», incluidos los textos médicos, sobrevivieron exclusivamente en los monasterios; entre estos, los benedictinos se interesaron por la práctica médica. Los monjes, sin embrago, solo practicaron la flebotomía y las cauterizaciones, con lo que la cirugía mereció escasa atención en la literatura médica en Latín durante los siglos VI-XI.

En el campo de la cirugía - como en otros campos de aprendizaje-- los autores árabes jugaron un papel fundamental en la conservación y recapitulación de los textos clásicos. Los primeros compiladores y editores tradujeron al árabe los originales primitivos indos, persas y griegos, y en particular el Epitome de Pablo de Egina. Los siete libros del Epitome fueron traducidos al árabe en el s. IX; de ellos, el libro sexto fue la base de 
los escritos árabes sobre cirugía; libro que, por otra parte, indicó el camino de la cirugía de la alta Edad Media y del renacimiento. Diversos autores islámicos trataron la cirugía. Rhazes (Abu Bark Muhammad Bin Zakariya Ar-Razi, 864-930) en el libro sexto de su Liber Medicinalis ad Almansoren; Haly Abbas (Ali ibn al-Abbas al-Majusi, 930-994) en el noveno libro (Practica) de su Libri Pantechni, y Avicena (Abu Ali al-Hussain ibn abadía Ibn Sina, 980-1037), cuyo Canon Medicinae - en parte referencia de la obra de Pablo de Egina- tuvo una gran influencia durante toda la Edad Media. Pero la fuente árabe de cirugía más importante es Abulcasis (Abu-1-Qasim Khalaf ibn al-Abbas al-Zahrawi, 936-1013), de Córdoba, cuyos treinta tratados de cirugía fueron traducidos al latín en el s. XII como Liber Alzahravii de Chirurgia. La impresión que se deduce de la obra quirúrgica islámica es que la utilización del bisturí pasó a segundo lugar, detrás de otras modalidades terapéuticas como la farmacia, la sangría y las ventosas. Cuando la cirugía era inevitable -se lamentaba Abulcasis- su nivel era más bien bajo; a la vez, la cirugía tenía una mala reputación. Sin embargo, el arsenal de instrumentos quirúrgicos era impresionante. Aparte de Abulcasis y, posiblemente, de Avenzoar (Abu Marwan Abd al-Malik Ibn Zuhr, 1091-1161), es poco probable que los autores citados practicaran ellos mismos la cirugía.

En Occidente y durante la Edad Media (siglos XII-XV) hubo un espectacular incremento en la literatura sobre la técnica quirúrgica, primero en latín y luego en las diferentes lenguas vernáculas. En parte, fue la traducción de los autores árabes al latín lo que proporcionó a Occidente las abundantes referencias quirúrgicas aludidas, principalmente hipocráticas. En Italia, menos cerrada que el resto de Europa, vio la fundación de las primeras Universidades nada más comenzar el s. XII, y allí revivió la cirugía teórica, fundamentalmente en Salerno - un centro de práctica médica desde mediados del $\mathrm{s}$. X. En esa ciudad y en aquel siglo (segundo tercio del s. XII) puede situarse el trabajo quirúrgico medieval más precoz de Occidente: una compilación anónimo de autores anteriores conocida como la cirugía de Bamberg.

A finales del s. XIII, el centro de los estudios médicos se trasladó a las Universidades del norte italiano (Bolonia, Padua, Verona). Los autores quirúrgicos de Bolonia continuaron la tradición latina; todos ellos mantuvieron la devoción galénica y, en grado variable, la tradición islámica. Por su parte, en Bolonia, en el año 1302, se llevó a cabo la primera disección de un cuerpo humano; ello con fines legales. A partir de 1315 se permitió un número limitado de disecciones humanas con propósito docente; disecciones que fueron realizadas por Mondino de'Luzzi (c12751326) y que le sirvieron de base para la realización de un libro de ana- 
tomía humana que terminó de escribir en latín en 1316 - impreso en Padua en 1478 - y en el que siguió, estrictamente, la doctrina galénica. Tales disecciones no tenían por objeto la nnseñanza de la cirugía, sino la demostración de las «bases científicas» de la medicina a los médicos.

La cirugía académica italiana se extendió, durante el s. XIV, a Francia. El principal autor quirúrgico del Medioevo tardío fue Guy de Chauliac (c. 1290-1368), un médico y cirujano formado en Bolonia. Su Chirurgia Magna fue traducida en varias ocasiones copando la literatura quirúrgica europea hasta el s XVIII. Por su parte, John de Ardene (130770) aparece como el primer especialista quirúrgico, quién centró su atención en la patología del recto y del ano. Tras la introducción de la pólvora en la guerra a mediados del s. XV, el número y la variedad de las heridas de guerra incrementaron significativamente. Los libros de cirugía en lenguas vernáculas estuvieron basados en la experiencia de los autores en el campo de batalla. Ambroise Paré (1510-1590), un cirujanobarbero del ejército francés, desarrolló nuevas formas de tratar las heridas y nuevas técnicas de amputación - a través de tejido sano y ligadura de los vasos en vez de la clásica cauterización- Paré fue hipocrático en cuanto al tratamiento de las fracturas, galénico respecto a la patología, siguiendo a Vesalio en la anatomía. Paré fue una figura de transición; supo combinar el empirismo -cuidadosa observación e innovación técnica- con la instrucción teórica, aunque no descuidó los tópicos de la época, principalmente la reproducción y los monstruos.

Numerosos cirujanos fueron anatomistas post-vesalianos; entre ellos, Marcus Aurelius Severinus (1580-1656), cuyo De Recondita Abscessuum Natura, de 1632, es considerado por los historiadores como el primer texto de patología quirúrgica. Sin embargo, la relación entre la «nueva anatomía» y la práctica quirúrgica es difícil de valorar. Durante el s XVII, la enseñanza de la anatomía llegó a ocupar un lugar preeminente en el currículo universitario de los médicos y, también, en el entrenamiento de los cirujanos; estos, todavía, bajo control gremial. Otros descubrimientos e innovaciones que ocurrieron durante el s XVII y que, con frecuencia, se integran en la historia de la cirugía, poco tuvieron que ver, en ese momento, con ella. El descubrimiento más importante de la época fue la circulación de la sangre por William Harvey (1578-1657) en el año 1628. Fue el trabajo de un aristotélico que acabó con la filosofía vitalista. El interés de la experimentación animal en varios países europeos durante el s XVII fue fruto de un debate filosófico. En este contexto, Richard Lower (1631-1691), un miembro del "Colegio Invisible» - el precursor de la Royal Society- experimentó en la transfusión directa de sangre entre animales y, en un caso, a un hombre. La transfusión de sangre con fines te- 
rapéuticos la intentó sin éxito, en 1667, el médico parisino Jean-Baptiste Denis (c1625-1704). Sin embargo, esas actividades a penas incidieron en la práctica diaria de los cirujanos del s. XVII, quienes, en alguna ocasión, comenzaron a elaborar detallados archivos de historias clínicas.

A lo largo del s. XVIII la práctica de la cirugía logró desembarazarse de los barberos y de las asociaciones gremiales; ello, particularmente, en el norte europeo. Paulatinamente se fueron estableciendo centros para la formación académica de los cirujanos. Tales cambios comenzaron en sur de Francia a finales del s. XVII. En París, el Colegio de Saint Côme, fundado en el año 1210, había disfrutado de una precaria existencia como un centro de cirugía académica hasta el año 1655 , cuando sus miembros fueron obligados a fusionarse con el gremio de barberos. Sin embargo, pocas décadas después, un edicto real permitió a los cirujanos iniciar un rápido proceso de emancipación; y en 1687, el celebrado caso de la fístula de Luis XIV, tratada con éxito por C. F. Felix (1650-1703), ayudó a incrementar el prestigio de la cirugía. Cursos de anatomía, de osteología y de técnica quirúrgica empezaron a comienzos del s. XVIII. Tales cambios marcaron el comienzo del final de la formación de los cirujanos por mero aprendizaje. En 1731 se otorgó el permiso para establecer la Académie Royale de Chirurgie y, en 1743, un edicto de Luis XV terminó con la unión entre cirujanos y barberos; cambios que contribuyeron a la posición preeminente que la cirugía ocupó en Francia, al menos, durante la primera mitad del s. XVIII. J. L. Petit (1674-1750) dominó la cirugía de la primera mitad del s. XVIII y atrajo numerosos estudiantes de toda Europa; entre ellos, Lorenz Heister (1683-1758) llegó a la cumbre de los cirujanos germanos; la Chirurgie (1718) de Heister, traducida al inglés como A General System of Surgery (1743), fue considerada por los cirujanos de finales del s XVIII como el primer tratado sistemático de la «ciencia de la cirugía».

La figura indiscutible de la cirugía científica durante los años finales del s. XVIII fue Scot John Hunter (1728-1793), el hermano menor de William Hunter, en cuya escuela privada de cirugía inició su andadura. John llegó rápidamente a ser un hábil disector, lo que le permitió fundar su propia escuela. Al contrario que William, que fue un notable profesional especializado en partos y que llegó a reunir una considerable fortuna, John invirtió todas sus energías y recursos al trabajo de investigación, acometiendo, en primer lugar, un extenso estudio sobre anatomía y fisiología comparada. Experimentó sobre los tópicos de la época, que vienen a ser los tópicos de siempre: inflamación, shock, vasculopatías y enfermedades venéreas. Sus cuatro tratados: Natural History of the Human Teeth (1771), On Venereal Disease (1786), Observations on Certain 
Parts of the Animal Oeconomy (1786) y Treatise on the Blood Inflammation and Gunshot Wounds (1794), se encuentran entre los escritos más importantes del siglo. S. J. Hunter coleccionó una enorme cantidad de piezas anatómicas, patológicas y embriológicas que pasaron al recién creado Royal College of Surgeons. Nombrado miembro de la Royal Society en 1767, sus aportaciones tuvieron que esperar varios años para que fueran incorporadas por la práctica quirúrgica, lo que no ocurrió hasta bien entrado el s. XIX.

Tan radical fue el cambio, que la instauración de la medicina clínica moderna exigió una ruptura ideológica completa: cirugía y medicina caminaban al mismo paso, de la mano. En la facultad de medicina de Edimburgo - meca, a mediados del s. XVIII, de los aspirantes de todo el mundo a ejercer la medicina -, Alexander Monroe primus (1697-1767), primer catedrático de Anatomía y de Cirugía, enseñaba un curso de cirugía teórico-práctica, en inglés, tanto a los estudiantes de medicina como a los aprendices de cirujanos. Ambos tipos de estudiantes se enfrentaban a «la teoría médica de la mano de la cirugía, del modo que opera la historia natural de las enfermedades». La nueva Medicina parisina, con una indiscutible base hospitalaria, vinculó los cirujanos a los hospitales de una manera más natural que los médicos internistas; de hecho, los cirujanos utilizaron los hospitales como centros de enseñanza de modo más sistemático. El cirujano Pierre Joseph Desault (1744-1795), en el Hôtel Dieu en París, introdujo la «enseñanza integral a la cabecera del enfermo» como una nueva forma de medicina clínica; por su parte, los cirujanos residentes aparecieron en los hospitales londinenses a principios de $1760 \mathrm{~s}$. En Francia se reconoce que la organización de las nuevas écoles de santé se debió al nuevo estilo de la práctica y de la organización de los cirujanos de París.

Durante las primeras décadas del s. XIX los cirujanos ocuparon una posición relevante entre la elite médica europea, y aunque la mortalidad quirúrgica permanecía escandalosamente elevada, los cirujanos más afamados intentaron una aproximación de la práctica quirúrgica a la teoría de la cirugía científica. La demanda sin límites de cadáveres por cirujanos y anatomistas terminó en escándalo, limitando el Anatomy Act de 1832 las circunstancias en que podían llevarse a cabo disecciones de cadáveres humanos. El ecuador del s. XIX marca un profundo corte en la historia de la cirugía. Señala la división entre la cirugía pre- y post-anestésica. Más que un corte debe hablarse de un periodo de transición que se inició con la implantación de la anestesia (1840s), permitió la institucionalización de la profesión médica y terminó con la aceptación de la antisepsia y la asepsia (1880s); acontecimientos que dieron un vuelco al hacer quirúrgico. 


\section{La revolución quirúrgica del siglo XIX: anestesia y antisepsia}

La eclosión anestésica en 1846 puede considerarse el punto de partida de la cirugía moderna. La rapidez con que la noticia del bloqueo de la sensación dolorosa durante una intervención quirúrgica se difundió por Europa, mostró el impacto de esta contribución de la medicina Americana a la Medicina. El 16 de octubre de 1846, el cirujano bostoniano J.C. Warren (1778-1856) operó un tumor cervical bajo anestesia inhalatoria administrada por W.T.G. Morton (1819-1868); la lectura pública de los resultados tuvo lugar durante una reunión celebrada el tres de noviembre (Figura 2). La anestesia por inhalación fue la herramienta anhelada para impulsar una poderosa comunidad quirúrgica (y obstétrica) en el contexto de una medicina universitaria bien asentada. La cirugía, considerada hasta entonces un mero oficio artesanal por la mayoría de los internistas y de los pacientes, fue reclasificada de inmediato. En enero de 1847, apenas cuatro semanas de la primera intervención indolora en Londres, J. Y. Simpson (1811-1870), en Edimburgo, administró cloroformo como anestésico inhalatorio para facilitar un parto complicado. Poco después, el dentista de Hartford, en Connecticut-USA, Horace Wells (1818-1917), publicó su trabajo sobre el empleo de óxido nitroso como

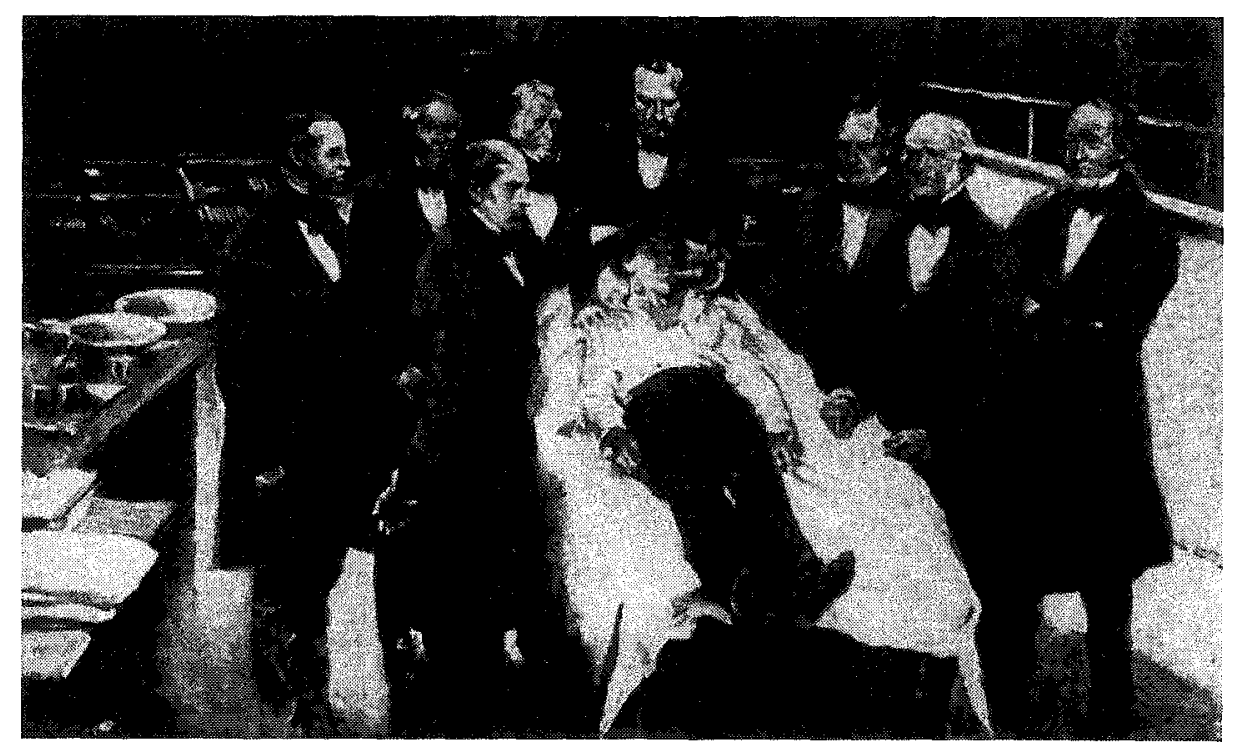

FiguRA 2. La primera demostración pública de anestesia quirúrgica. Boston, 15 de octubre de 1846. Doctores H. J. Bigelow, A. A. Gould, J. Mason Warren, J. C. Warren, W. T. C. Morton, Samuel Parkman, S.D. Townsend y George Hayward. En: www.tecsoc.org/pubs/history/pics/anesthesia.jpg. 
anestésico. De este modo, tres agentes anestésicos inhalatorios (éter, cloroformo y óxido nitroso) estuvieron disponibles en unos pocos meses; ello significó una verdadera revolución que causó un vasto y profundo debate en los círculos profesionales y legos sobre los aspectos éticos y médicos del control del dolor. El debate sobre los pros y los contras del éter, del cloroformo y de otros gases, y sobre la idoneidad de la mezcla más adecuada o de la secuencia de su utilización, se prolongó hasta la Primera Guerra Mundial. De cualquier modo, la anestesia estableció la transición entre el papel del cirujano como mero practicante distinguido y su figura como clínico e investigador.

Retornado a los años finales de la década de $1840 \mathrm{~s}$, se deduce de los archivos de historias clínicas de los hospitales -que por aquellas fechas era algo completamente novedoso- y de diversas fuentes documentales, que la introducción de la cirugía sin dolor -aunque aclamada por los pacientes- no supuso avance alguno en el éxito de las intervenciones quirúrgicas. La mortalidad intra- y post-operatoria siguió siendo elevada a causa de las hemorragias y de las infecciones postoperatorias. Faltaba teoría que soportara la intrepidez quirúrgica auspiciada por la anestesia. Providencialmente, poco después del nacimiento de la anestesia, se logró el primer éxito frente a las infecciones quirúrgicas. Ignaz P. Semmelweis (1818-1865) demostró en Viena, en 1848-9, que la fiebre puerperal era una septicemia contagiosa que podía prevenirse mediante el lavado de las manos con agua y con jabón, utilizando un cepillo de uñas y sometiéndolas a un último aclarado con agua clorada, antes de proceder al examen transvaginal. Esta observación, y su contribución escrita, fueron totalmente empíricas y no tuvieron fundamento teórico alguno, por lo que solo tuvieron un reconocimiento parcial por la comunidad académica. En paralelo y de manera independiente, una escuela de «cleanliness and cold water» se estableció en Londres de la mano de T. S. Wells (18181897). Desde 1860, Wells se lavaba con agua limpia, utilizaba compresas limpias durante las intervenciones, cosía con hilo metálico y admitía en el quirófano muy pocos observadores y siempre que no hubieran asistido a alguna autopsia en los siete días precedentes.

Ambos procedimientos podrían etiquetarse de «asépticos»; esto es, todas las partes en contacto con el paciente (manos, instrumentos, lencería) estaban relativamente libres de gérmenes. Ni Semmelweis ni Wells eran conscientes de la patogenicidad de los microorganismos tal como hoy la entendemos. Por aquellas fechas, el respaldo teórico, establecido en el s XVIII aunque era mucho más antiguo, asumía que las infecciones estaban causadas por miasmas -emanaciones de fuentes no humanas-y por contagios -emanaciones de origen humano que padecían 
enfermedades-. Todas las emanaciones se transmitían por el aire, por lo que se preconizaba la ventilación y el control del hacinamiento como medidas preventivas. Para la cirugía, el dogma higienizante imperante establecía el tratamiento abierto de las heridas: la ventilación y el aire fresco favorecerían el proceso natural de cicatrización, en el que la infección era considerada un componente natural del proceso.

En este debate, Joseph Lister (1827-1912), Profesor de Cirugía en Glasgow, publicó, en 1867, una serie de artículos en The Lancet; el primero: «On a new method of treating compound fractures, abcesses, etc», $\mathrm{y}$ el último: «Illustrations of the antiseptic system of treatment in surgery». La antisepsis -teoría aportada en la serie de publicaciones-consistía en la destrucción o en la supresión de los agentes de la infección de la herida por desinfectantes. La actitud de Lister dependía de dos supuestos teóricos completamente nuevos respecto de la infección: el primero, que los gérmenes, que eran ubicuos, eran los agentes causantes de las infecciones; $y$, segundo, que la infección no era un componente normal del proceso de curación de las heridas. Las dos hipótesis chocaban frontalmente con el concepto establecido y que había probado su eficacia mediante las medidas higiénicas adoptadas.

La nueva hipótesis planteada por Lister derivaba del trabajo de Louis Pasteur (1822-1895) sobre la fermentación y la putrefacción, fenómenos que interpretó como procesos biológicos debidos a la acción de las bacterias y/o de las levaduras, en presencia y en ausencia de aire (1859-1863), y de sus observaciones sobre la fermentación del vino por microorganismos (1868). Sin embargo, la analogía entre los fenómenos estudiados por Pasteur y los estudiados por Lister, no pudo ser demostrada experimentalmente (Figura 3). De este modo, el método de Lister solo pudo convencer por sus resultados. Lister los presentó como una comparación estadística de las tasas de mortalidad de fracturas con minuta antes y después de la introducción del tratamiento de los vendajes con ácido carbólico (fenol). Sus propiedades desinfectantes o más bien desodorantes (dirigidas contra las «emanaciones») habían sido ya descritas por F. J. Lemaire (1814-1846) en Francia, en 1860. En efecto, Lister había elegido el fenol entre otras sustancias conocidas por su efecto desodorizante. Aunque es posible que Lister presentara una "estadística sesgada", como sugiere el estudio actual de su trabajo, no cabe duda que los resultados presentados impresionaron a sus contemporáneos, más preocupados de los resultados que por la justificación teórica: en los años 1864-66, murieron 16 de sus 35 pacientes amputados (46\%); entre 1867-9, solo murieron 6 de 40 (15\%).

Por fin, las bases científicas de la infección y del método aséptico, fueron establecidas en Alemania, por esas mismas fechas. Se estableció, pri- 

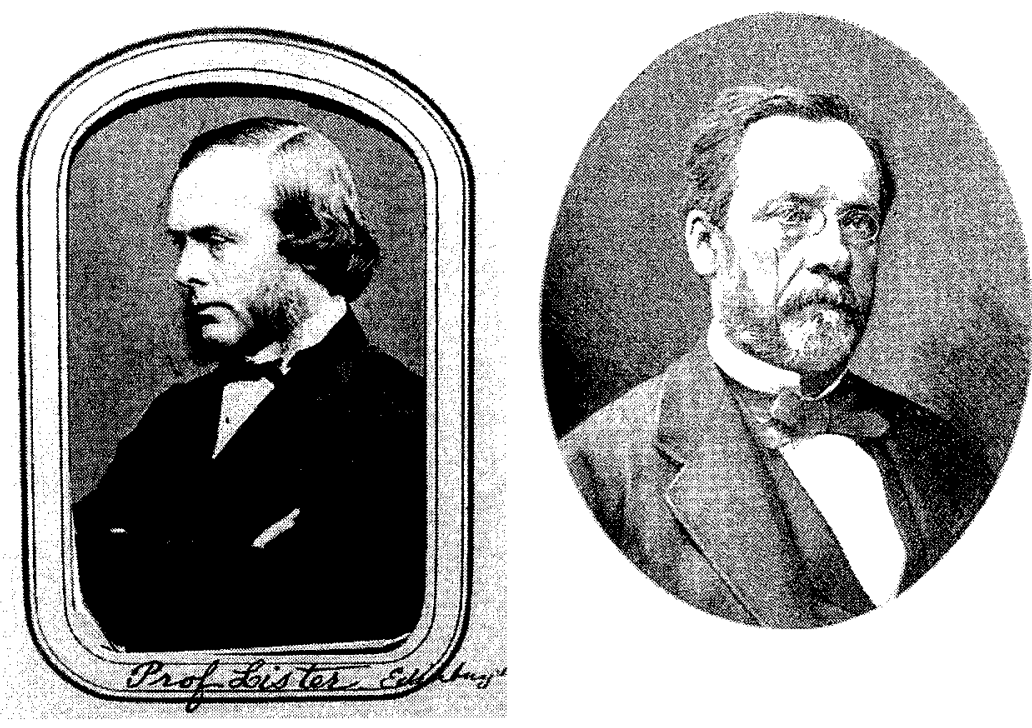

FrguRA 3. Joseph Lister (1827-1912) y Louis Pasteur (1822-1895) introdujeron el método antiséptico.

mero, la hasta entonces ausente base experimental de la teoría bacteriana de la infección quirúrgica; ello, al demostrarse la posibilidad de cultivar e identificar gérmenes en el laboratorio y, con ellos, provocar infecciones quirúrgicas experimentales específicas. En segundo lugar, la bacteriología proporcionó los criterios objetivos para evaluar la eficacia de las medidas adoptadas para prevenir o para luchar contra la infección quirúrgica. El trabajo experimental de los bacteriólogos despejó cualquier duda sobre la necesidad de la presencia de bacterias para que se produjera una infección en una herida. El examen bacteriológico de frotis tomados de la piel del cirujano, del paciente, de las ropas y del instrumental, se convirtió en una rutina. La evaluación bacteriológica también incluyó la higiene del hospital y de las lavanderías, y la acción bacteriostática del jabón.

Theodor Kocher (Figura 4), aunque seguidor de los métodos de Lister, observó la toxicidad y en ocasiones la ineficacia del fenol, lo que le llevó a hervir sus instrumentos a partir de 1886. Por su parte, el bacteriólogo E. Travel (1858-1912) introdujo el método de esterilización rápida mediante vapor a presión. Fue también Kocher quién insistió en el principio listeriano del manejo cuidadoso de los tejidos, desde la incisión de la piel - que debía ser paralela a las líneas cutáneas - hasta una hemostasia cui- 

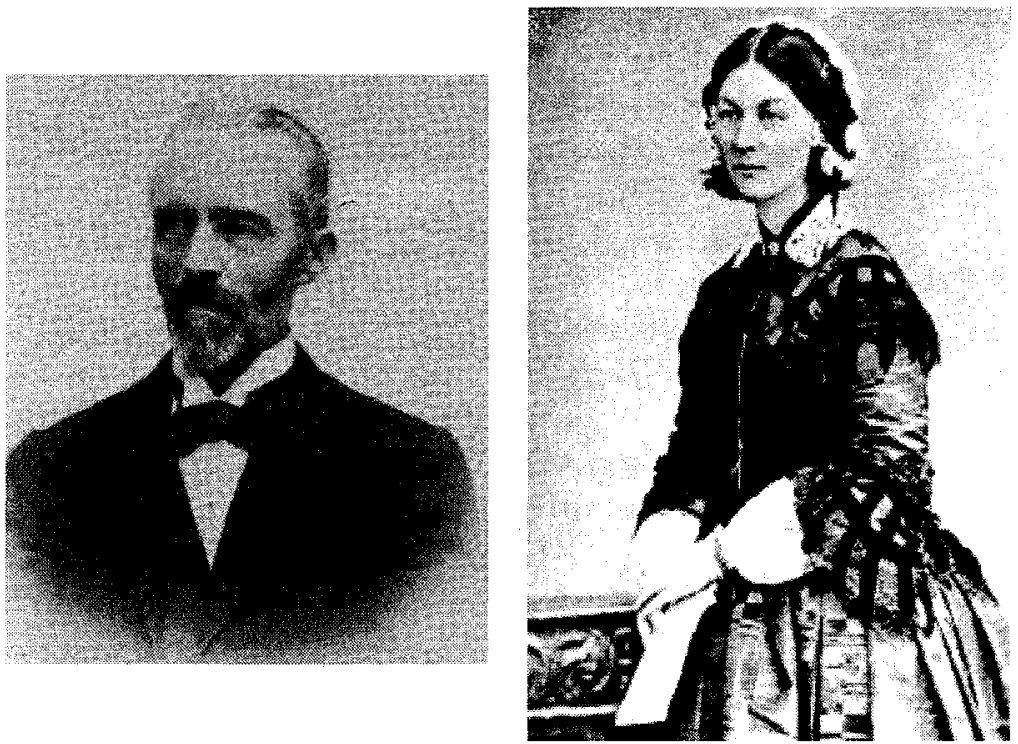

Figura 4. Theodor Kocher (1843-1910), Premio Nobel 1909 "por su trabajo sobre la fisiología, la patología y la cirugía de la glándula tiroidea", y Florence Nightingale (1820-1910), fundadora de la enfermería moderna.

dadosa (pinzas hemostáticas de Kocher). Lesión tisular y hemorragia sobre las que descansaban las relaciones «lesión-infección» y «hematomainfección» que, durante algunos años, dominaron la fisiopatología quirúrgica. Kocher alertó que la asepsia-antisepsia no debía ser causa de desatención de las bases anatómicas y fisiológicas del proceso de cicatrización. El cirujano von Mikulicz-Radecki y el microbiólogo C. Flügge (1847-1923) demostraron que la conversación durante el acto quirúrgico incrementaba el riesgo de infecciones (gotas o aerosol de Flügge); riesgo que podía ser controlado con el uso de mascarillas. En 1890, William S. Halsted (1852-1922), del Hospital Johns Hopkins, impuso la utilización de guantes de goma elástica; costumbre que contó con una gran resistencia por su costo y por la reducción del tacto. Sin embargo, a finales del s XIX, la profilaxis antiséptica pre-operatoria y los métodos asépticos quirúrgicos estuvieron bien implantados por todos los cirujanos. La utilización por los cirujanos de batas esterilizadas, de mascarillas y de guantes - que Lister jamás utilizó -, se fue imponiendo paulatinamente y sin grandes resistencias a finales de la década de $1870 \mathrm{~s}$.

En general, hasta 1900, las operaciones se caracterizaban por su rapidez, una reliquia de las eras preanestésica y preantiséptica. La adqui- 
sición de nuevas técnicas gracias al desarrollo de numerosos instrumentos facilitó el trabajo de los cirujanos; sin embargo, la cirugía seguía centrada en la intuición, la perseverancia y, sobre todo, en el brillo de cada maestro. Solo unas pocas intervenciones llegaron a estandarizarse de manera internacional. Si la cirugía estuvo dominada por la idea de la resección y extirpación en íntima relación con el concepto virchowniano de la enfermedad, ello también exigió la incorporación de métodos de cierre de la herida quirúrgica. Por ejemplo, la sutura intestinal abrió un nuevo territorio a la cirugía: la cirugía gastro-intestinal. Técnica de sutura que, una vez sistematizada y elaborada, permitió abordar cualquier víscera hueca con la certeza de conseguir restaurar la continuidad de la pared.

Como resumen sirva de ejemplo la estadística completa que Theodor Billroth (1829-1894) publicó de su trabajo como director de las clínicas quirúrgicas universitarias de Zurich (1860-7) y de Viena (1867-8), en las que atendía 700 pacientes al año. El estudio se refiere, principalmente, a enfermedades de localización superficial a menudo complicadas con infecciones; sus métodos eran fundamentalmente conservadores, y solo como último recurso, empleaba métodos radicales (amputación o resección) con una elevada mortalidad por complicaciones hemorrágicas o infecciosas.

La expansión de la práctica quirúrgica y el establecimiento de la investigación en cirugía se reflejaron en el incremento sostenido de trabajos presentados a las reuniones de las recién creadas sociedades científicas quirúrgicas. Las series germánicas, que comenzaron en 1872, el cáncer fue un tema principal; tema que se repetiría como el tópico central de los congresos. Hubo una producción continua de trabajos sobre el cáncer que, en términos generales, representaron el $20 \%$ del total de las publicaciones. Durante aquellos años los órganos más estudiados fueron el tracto gastro-intestinal (26.5\%), el tiroides (18\%), la mama (16.2\%) y el hueso $(12.9 \%)$. El objetivo terapéutico era la erradicación total del tumor, lo que promovió intervenciones mutilantes que se acompañaban de un índice de mortalidad perioperatoria muy elevado. Otro de los temas estrella seguía siendo las infecciones quirúrgicas agudas (apendicitis, colecistitis) y crónicas (tuberculosis extrapulmonar, osteomielitis). El tratamiento de las fracturas ocupó un lugar destacado a raíz de la Guerra Franco-Prusiana, circunstancia que abrió la puerta a una nueva especialidad quirúrgica: la cirugía de guerra. Por su parte, tumores e infecciones provocaban obstrucción o estenosis, sobre todo en el tubo digestivo, en el árbol respiratorio y en el tracto urogenital; la «fisurización» (traqueostomía, cecostomía), una técnica sencilla y segura, ofreció alivios espectaculares. Con todas esas técnicas, relativamente sencillas y seguras, la cirugía entró en 
su «edad de oro» mostrándose la rama incuestionablemente más resolutiva de la medicina. En esta revolución sin precedentes, llevada a cabo por una sola generación, los países de habla alemana ocuparon una posición de liderazgo consolidada a finales del s XIX. La práctica clínica, la enseñanza y la investigación, coincidieron en los departamentos de cirugía de las facultades de Medicina de Austria, Alemania y Suiza. Esos departamentos universitarios con su clásica y clara organización jerárquica fueron ejemplo para otros países, tal como EE.UU (Universidad de John Hopkins) y Holanda.

La expansión científica en Alemania se reflejó en la fundación de cuatro revistas dedicadas exclusivamente a cirugía: Archiv für klinische Chirurgie (1861), Deutsche Zeitschrift für Chirurgie (1872), Centralblatt für Chirurgie (1874) y Beiträge zur klinischen Chirurgie (1886). Por otra parte, se fundaron varias sociedades quirúrgicas nacionales; la primera fue la alemana (1872). La American Surgical Association, la primera de las sociedades quirúrgicas de EE.UU. se constituyó en 1880, que publicó los Annals of Surgery (1885), la primera revista quirúrgica moderna no alemana. En Inglaterra y en Francia la cirugía siguió publicándose en las revistas médicas generales. El British Journal of Surgery data de 1913. Las sociedades quirúrgicas Italiana y Francesa se fundaron en 1882 y 1884, respectivamente; la Holandesa en 1902 y la Suiza en 1913. La Societè Internationale de Chirurgie se estableció en Bruselas en 1905. Con todo ello, la cirugía había llegado a su mayoría de edad profesional.

Ya en el nuevo siglo, un espíritu de optimismo quirúrgico invadió a los profesionales, a los hospitales, a los gobiernos y a los pacientes. En 1909, el cirujano T. Kocher recibió el Premio Nobel en Fisiología o Medicina por su trabajo en la fisiología, la patología y la cirugía del tiroides. Junto a ello, Florence Nightingale (1820-1910) profesionalizó la enfermería, un precedente obligado de la moderna medicina basada en el hospital, en particular la cirugía (Figura 4). La demanda de cuidados pre- y post-operatorios, las estrictas reglas exigidas por la antisepsia y la asepsia y la exigencia de un instrumental cada vez más complejo, transformaron la práctica de la cirugía en un trabajo en equipo.

En resumen, el periodo que comprende la «primera revolución quirúrgica», que se extendió desde mediados del s. XIX hasta la Primera Guerra Mundial, estuvo basado, principalmente, en la anestesia, la asepsia y la anatomía patológica; una estrategia que dictó el carácter localista y exerético de la cirugía; tal periodo fue excepcionalmente rico en ideas y en nuevas técnicas quirúrgicas que se acompañaron de una letalidad perioperatoria progresivamente decreciente. Numerosas intervenciones en el tracto gastro-intestinal, sistema nervioso, tiroides, ma- 


\section{Pedro García Barreno}

mas, huesos y vasos sanguíneos, se fueron incorporando con el cambio de siglo. E. von Küster (1839-1930), de Marburg, quien había realizado por primera vez con éxito una intervención plástica para tratar la hidronefrosis (1892), manifestó en una conferencia sobre la situación de la cirugía urológica que "es imposible no tener la impresión de que el trabajo principal ya ha sido hecho y de que nuestros sucesores solo tendrán que hacer pequeñas aportaciones». Los años que precedieron a la Primera Guerra Mundial representaron la edad de oro de la cirugía en un sentido clásico, pero con estrechez de miras: se habían conquistado las cavidades y los órganos del cuerpo humano. Aunque las disputas entre cirujanos e internistas sobre la oportunidad del tratamiento quirúrgico versus el conservador en diferentes patologías como la apendicitis se habían decantado por el primero, se mantenía el problema subsidiario de la aceptación social de la cirugía por los médicos y por los pacientes en las enfermedades crónicas. Las complicaciones inmediatas de la cirugía (embolismo, hemorragia) eran temidas. Los pacientes solían temer más la inducción de la anestesia por inhalación que la propia intervención. Además, métodos alternativos, como la radioterapia en el cáncer y la helioterapia en la tuberculosis extrapulmonar, minaban la credibilidad quirúrgica. A menudo, la decisión para intervenir en una enfermedad crónica dependía de la condición social del paciente más que de consideraciones médicas.

Sin embargo, los cirujanos más comprometidos fueron conscientes de que si la cirugía se conformaba con llegar a dominar diversas técnicas de manera rutinaria, dejando de lado los fundamentos científicos, volvería a encasillarse en un mero oficio artesanal. George W. Crile (1864-1943) de Cleveland (Ohio, EE.UU), pionero de los trabajos experimentales sobre el shock, concluyó en una reunión en Londres, en 1910: «... parece que la era del triunvirato anestesia-asepsia-anatomía patológica ha alcanzado su cenit ... ¿ no estaremos entrando en el umbral de la era de la fisiología, de la interpretación de las leyes del organismo?»

\section{La segunda revolución quirúrgica: la especialización}

Hasta la Primera Guerra Mundial, la operabilidad había dependido, en principio, de la experiencia, de la intuición y de la habilidad y capacidad técnica del cirujano. Si bien todo ello sigue siendo válido, en especial en la cirugía de urgencia, no lo es tanto en la cirugía electiva, en la que la indicación y el manejo terapéuticos dependen de la precisión diagnóstica, de técnicas quirúrgicas sofisticadas y de las posibilidades de trata- 
miento pre- y postoperatorio y de la disponibilidad de unidades de cuidados intensivos. Mientras que durante el primer periodo de la cirugía moderna la curabilidad fue el factor dominante para determinar la operabilidad, y durante su segundo periodo fue el restablecimiento de la función el determinante prioritario, el tercer periodo se caracteriza por la posibilidad de reemplazar los órganos enfermos. Por otro lado, el desplazamiento de la cirugía por otras formas de tratamiento, la sustitución de técnicas convencionales por otras radicalmente nuevas y la evaluación de los resultados -incluida la calidad de vida- mediante ensayos clínicos son, también, factores determinantes. Pero ante todo, la especialización.

Alrededor de 1910, las herniorrafias y las apendicectomías representaban las intervenciones quirúrgicas más frecuentes (30\%); junto con otras operaciones gastrointestinales representaban el $40 \%$ de la práctica quirúrgica en la clínica de Kocher, en Berna, que se ocupaba de la práctica totalidad de la cirugía a excepción de las enfermedades oftalmo- y otorrinolaringológicas. Esos porcentajes, que se mantenían en la década de 1950s, justificaban la existencia de «cirujanos generales» con un amplio abanico de competencia técnicas, que se enfrentaban desde el hematoma subdural al cáncer de pulmón; atendiendo, también, los órganos endocrinos, las vísceras abdominales, los vasos periféricos, y la cirugía ortopédica, la traumatología y la urología. A principios de 1990s, las herniotomías y la cirugía gastointestinal representaban, en la misma clínica, el $10 \%$ de la actividad. La neurocirugía, la urología, la cirugía torácica y la ortopedia, dominan la actividad.

La fragmentación de la cirugía en especialidades comenzó cuando diferentes campos quirúrgicos fueron tomando cuerpo alrededor de nuevos instrumentos diagnósticos: el oftalmoscopio, introducido por $\mathrm{H}$. Helmholz (1821-1894) en 1851; el laringoscopio por M. García (1805-1906), en 1854, o el otoscopio por A. T. von Troeltsch (1829-1890), en 1860. El fundador de la oftalmología y el creador de la oftalmología moderna fue $\mathrm{Al}$ brecht Graefe (1828-1870) de Berlin, quién introdujo, entro otras cosas, la iridectomía en el glaucoma y la extracción de las cataratas. En 1880, las 27 facultades de medicina de habla alemana disponían de una cátedra de Oftalmología que incluía la cirugía como especialidad distinguida. La institucionalización de la otorrinolaringología fue más lenta. En 1880 existían profesores extraordinarios de la especialidad en casi el $70 \%$ de las universidades germanas, porcentaje que se incrementó hasta un $80 \%$ en la década de 1950s. La especialidad emergió en Alemania y en Austria de la mano de von Troeltsch en Würzburg y de A. Politzer (18351920) en Viena. Cientos de médicos americanos viajaron a Viena en la década de 1900 s para aprender las técnicas endoscópicas y oftalmoscópicas. 
Von Troeltsch planteó el tratamiento quirúrgico de la mastoiditis, y Politzer ideó un método eficaz para permeabilizar la trompa de Eustaquio (1863) y estableció la otosclerosis como una entidad clínica definida (1893). Hubo que esperar a 1937 para que M. L. J. Sourdille (1885-1961) y J. Lempert (n. 1890) estandarizaran la intervención por sordera mediante la fenestración del canal semicircular externo, y a 1952 para que esta fuera reemplazada por la movilización del estribo por S. Rosen ( $\mathrm{n}$ 1897).

La tradición ancestral litotomista persistió hasta los trabajos de los pioneros de la moderna litotricia, como J. Civiale (1792-1867) y C. L. S. Heurteloup (1793-1863), quienes propusieron la desintegración de los cálculos en la vejiga. Como una especialidad moderna, la urología se desarrollo en el ambiente de la cirugía general alrededor de las nuevas posibilidades diagnósticas. Tras la primera nefrectomía por G. von Simon (1824-1876) en 1869, surgió la primera generación de cirujanos comprometidos con la urología: H. Thompson (1820-1904) en Londres; en Berlin, J. Israel (1848-1926) que logró disminuir la morbilidad por nefrectomía hasta un 10\%, y F. Guyon (1831-1920) y L. von Dittel (1815-1898) en Viena, donde M. Nitze (1848-1906) dirigió una gran policlínica en la que se desarrolló un cistoscopio con luz eléctrica abriendo las puertas a la cirugía endoscópica urológica. Los avances diagnósticos incluyeron el cateterismo ureteral (Hospital Johns Hopkins, 1893) y la visualización incruenta de cálculos mediante rayos X; esto último, al año siguiente del descubrimiento de la nueva forma de radiación. En 1905 se realizaron los primeros cisto- y pielogramas retrógrados por F. Voelker (1872-1955) y A. von Lichtenberg (1880-1948), respectivamente. Aunque la urografía retrógrada supuso un gran avance en el diagnóstico de localización, fue un método nada fisiológico que se siguió, con frecuencia, de infecciones pielonefríticas. El gran cambio llegó con la urografía endovenosa, introducida por von Lichtenberg en 1929. La cirugía de la hipertrofia de próstata mediante resección data de los 1890s en Italia (E. Bottini, 18371903), en Inglaterra (prostatectomía suprapúbica por E. Fuller, 1858-1930) y los EE.UU. (prostatectomía perineal por F. S. Watson, 1853-1942). Por su parte, H. Young (1870-1945) realizó la primera operación radical en cáncer de próstata (1905). Tales intervenciones, y la nefrectomía unilateral en la tuberculosis renal, fueron ejemplos típicos del periodo anatomopatológico de la cirugía. Particularmente en urología, la transición al segundo periodo - más preocupado por los aspectos funcionales - estuvo marcada por la introducción de la pielografía endovenosa, que permitió un diagnóstico sistémico y funcional del riñón y de las vías excretoras. La nefrectomía, que se practicaba en el $80 \%$ de las enferme- 
dades renales unilaterales disminuyó hasta el 20\%. Se intentaron las primeras operaciones plásticas para normalizar el flujo de orina en casos de estenosis; a la vez, la extirpación de la vejiga en casos de carcinoma fue completada por R. C. Coffey (1869-1933), quién condujo los uréteres al intestino grueso (1911), y, tras la Segunda Guerra Mundial, se diseñaron reservorios vesicales con segmentos intestinales por E. M. Bricker (n. 1908) en EE.UU y por Seifert en Alemania. La urología es también un buen ejemplo de la evolución de la cirugía en su tercer periodo. Fue uno de los primeros campos en los que la tumorectomía fue desplazada por la radioterapia; A. L. Gray (1873-1932) la aplicó en el carcinoma de vejiga (1906) y, poco después, en el cáncer de próstata. Tumor este último, que fue tratado con hormonas (1901); por este trabajo sobre cánceres hormono-dependientes, C. B. Huggins (1901-1997), de Chicago, compartió un Premio Nobel en 1966 (el otro premiado fue Peyton Rous por sus trabajos sobre inducción tumoral por virus). La urología quirúrgica se vio muy influenciada por la sonografía (1955), que marcó cambios análogos a los que siguieron a la pielografía endovenosa en los 1920s. La ecografia es de fácil manejo, exige un equipo relativamente sencillo y evita la irradiación; además, proporciona una guía precisa hacia el campo operatorio, permite la diferenciación neta entre tumores, quistes y cálculos, y facilita la punción renal y de las vías urinarias bajo control visual, lo que permite la trituración y extracción de cálculos con endoscopios especiales. Tales sistemas ópticos permitieron el despegue de la urología endoscópica. En los 1980s, el cirujano experimental W. Brendel (n. 1922) y el urólogo E. Schmidt (n. 1920), en Munich, publicaron los primeros resultados clínicos con litotricia ultrasónica; técnica que, como en los otros casos antes citados, abrió nuevas espectativas en cirugía.

Lo mismo sucedió en los campos quirúrgicos más tradicionales; la cirugía digestiva y la ortopedia cambiaron progresivamente sus técnicas debido a la llegada de nuevos instrumentos y materiales. Cuando a finales del s. XIX las nuevas técnicas de sutura abrieron nuevos territorios, la cirugía pasó por una nueva fase experimental a partir de la década de 1950s. El Instituto de Ciencia de Moscú para Aparataje e Instrumentación Quirúrgicas, de la mano de Gudov y de Androsov, desarrollaron una serie de aparatos para sutura automática. La sutura automática fue una de las condiciones fundamentales para abordar la resección rectosigmoidea por vía abdominal, lo que permitió la resección tumoral conservando la función del esfínter anal y, con ello, asegurar la continencia fecal.

El rápido declinar de la tuberculosis - a pesar del nuevo rebrote- y otras enfermedades crónicas es otro ejemplo del cambio en el espectro de la patología quirúrgica: las resecciones y las amputaciones de huesos y 
articulaciones por enfermedades infecciosas son la excepción en el mundo Occidental. Sin embargo, la experiencia de esa cirugía osteoarticular desarrollada a lo largo de casi cien años, ha proporcionado las bases de la osteosíntesis y del implante de articulaciones artificiales. La ortopedia, comprometida en un principio con las deformidades óseas congénitas, llegó a ser cirugía ortopédica cuando extendió su territorio a las anomalías del desarrollo y a las discapacidades debidas al envejecimiento, a infecciones o a lesiones del aparato locomotor. Los tratamientos se basaban en largos periodos de reposo, férulas y, en el caso de lesiones abiertas, en la amputación. A partir de la década de 1870s se impusieron los tratamientos quirúrgicos: osteotomías, autoinjertos óseos y autotrasplante de tendones y de piel. La introducción de la sierra mecánica por el americano F. H. Albee (1876-1945) en 1909 condujo a una nueva era en los injertos de hueso. La historia de los implantes-trasplantes es un buen ejemplo de que es posible disponer de las ideas correctas en el tiempo equivocado. Así, los métodos empíricos de fijación interna en las fracturas del cuello femoral y de los reemplazamientos totales de la articulación de la rodilla utilizando metal y marfil, respectivamente, publicados en Alemania (por ej., T. Gluck (1853-1942) en 1890) no contaban con el mínimo apoyo tecnológico (metalurgia, biomecánica, biocompatibildad) ni con el mínimo conocimiento de fisiología ósea. El primer tratado sobre fijación interna de las fracturas mediante cerclaje, sutura o impactación por el cirujano francés L. Bérenger-Féraud (1832-1900) tuvo el mismo inconveniente en 1870 , e igualmente la introducción de la técnica y del nombre de osteosíntesis por A. Lane (1856-1938) de Londres y A. Lambotte (1866-1955) de Bruselas, en 1907. El empirismo de ingenio perduró hasta la década de 1960s. Las primeras investigaciones experimentales en animales sobre los requerimientos metalúrgicos y mecánicos de los implantes se llevaron a cabo en EE.UU. e Inglaterra antes de la Gran Guerra. En los 1920s se disponía de muy poca información sobre el hueso como tejido vivo; ello forzó a que anatómicos, fisiólogos y cirujanos comenzaron a trabajar conjuntamente. Tal aproximación dio pronto resultados; una década después, la vitamina $\mathrm{D}$ mostraba sus propiedades de prevenir y de curar el raquitismo sin necesidad de ortopedia. Idéntica estrategia fue también la clave de la moderna osteosíntesis científicamente fundamentada y desarrollada por R. Danis (1880-1962) en Bruselas. En 1958 se constituía la Swiss Arbeittsgemeinschaft für Osteosynthesefragen., grupo multidisciplinar que desarrolló numerosas intervenciones estándar. De la misma manera que asepsia desterró la idea de que el camino normal de la curación de las heridas era la supuración, la posibilidad de fijación rígida por compresión dejó de lado la exigencia de provo- 
car un callo abundante como garantía de consolidación. Las agujas intramedulares de G. Küntscher (1900-1972) de Kiel aún tienen vigencia en determinados casos. En cuanto a las prótesis, un comité en EE.UU catalogó, en 1954, cerca de 40 tipos de endoprótesis femorales; ninguno de ellos fue considerado satisfactorio. En 1961 se abrió una nueva etapa cuando John Charnley (1911-1982), de Manchester, publicó su trabajo sobre artroplastias con bajo perfil de fricción utilizando una cabeza y cuello femorales metálicos, y un acetábulo plástico. El éxito trasladó tales principios a la rodilla, tobillo y otras articulaciones.

La cirugía del sistema nervioso fue otro campo que se desarrolló como una especialidad en paralelo a los avances en las técnicas diagnósticas. Hacia 1890, la denominada topografía craneocerebral mediante «craneotomos» inició la localización de diferentes centros funcionales en la corteza; pero, en la casi totalidad de los casos, el cirujano dependía del diagnóstico del neurólogo. La visualización de los ventrículos y del cerebro mediante ventrículo- y pneumo-encefalografía por W. Dandy en 1918 y 1919, respectivamente, dio un vuelco a la situación. A estas técnicas siguieron la mielografía en 1921 (J. A. Sicard, 1872-1929) y la angiografía cerebral en 1927 (A. C. de Egas Moniz, 1874-1955). El primer neurocirujano, como tal, antes de la Primera Gran Guerra fue Harvey Cushing (1869-1939), en Baltimore y en Boston, quién fue también un afamado anatomopatólogo. Hizo aportaciones pioneras sobre la hipófisis y el hipotálamo, desarrolló la electrocirugía e introdujo el uso de clips de plata para la hemostasia. Cushing y otros neurocirujanos de su generación coparon la neurocirugía en sus comienzos. La Society of Neurological Surgeons se fundó en 1920 y, en 1944, comenzó la publicación del Journal of Neurosurgery. En Europa se distinguó, especialmente, R. Leriche, quién aportó la cirugía del sistema nervioso autónomo; técnica que tuvo vigencia hasta los 1960s en que fue desplazada por la farmacoterapia específica. Por su parte, la psicocirugía -por ej., la leucotomía para la esquizofrenia crónica intratable (1936), por la que el portugués Egas-Moniz compartió con W.R. Hess el Premio Nobel de Fisiología o Medicina 1949 (Figura 5) - fue una intervención típica del segundo periodo de la cirugía pero que, en la época actual, ha quedado completamente obsoleta. La introducción de la tomografía computarizada y de la resonancia magnética, las técnicas estereotáxicas y de navegación, el desarrollo de las técnicas «key-hole» y de visualización en tiempo real, y los trasplantes celulares, han hecho de la neurocirugía una de las especialidades quirúrgicas más avanzadas.

Para la mayoría, la cirugía cardiaca es el prototipo del avance quirúrgico logrado a lo largo del s. XX; también, aquella especialidad donde la 


\section{Pedro García Barreno}

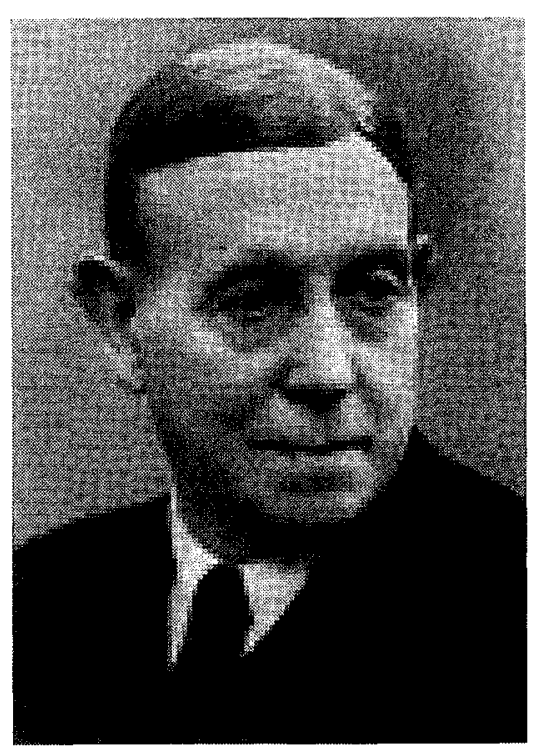

Figura 5. Antonio Caetano de Abreu Freire Egas Moniz (1874-1955) recibió el Premio Nobel 1949 «por su descubrimiento del valor terapéutico de la leucotomía en ciertas psicosis».

presencia tecnológica ha sido más espectacular. Pueden distinguirse tres etapas en la especialización cardioquirúrgica: cirugía extracardiaca, cirugía intracardiaca ciega (a corazón cerrado) y cirugía extracardiaca controlada (a corazón abierto). Durante la fase pionera extracardiaca las intervenciones se centraban en afecciones pericárdicas y la corrección de algunas cardiopatías congénitas. En 1896, L. Rehn (1849-1930) suturó, con éxito, una herida cardiaca. Las correcciones de las anomalías vasculares humanas fueron abordadas en Boston en 1939, cuando R. E. Gross (1905-1989) y J. P. Hubbard (n. 1903) realizaron, con éxito, una ligadura de un ductus arterioso patente. En 1945, A. Blalock y H. Taussing (18981986), del Hospital John Hopkins, corrigieron una estenosis pulmonar mediante la creación de un ductus arterioso artificial. En el mismo año, C. Crawfoord (1899-1984), en Estocolmo, resecó una coartación congénita de la aorta y, en 1951, C. Dubois (m. 1914), en París, se enfrentó a un aneurisma de la aorta abdominal terminal que reemplazó utilizando tejido venoso homólogo. El periodo de cirugía intracardiaca ciega comenzó antes de la Primera Guerra Mundial. T. Tuffier (1857-1929) dilató una estenosis valvular aórtica en 1912 y, en 1925, en Londres, H. Souttar (1875-1964) realizó una comisurotomía en una estenosis mitral; ambas operaciones fueron un éxito. Sin embargo, otras intervenciones realiza- 
das entre 1923 y 1928 en Boston no fueron efectivas; ello, por convertir las estenosis en graves insuficiencias. El despegue definitivo tuvo lugar en los años 1947 y 1948: H. G. Smithy (1914-1948), C. P. Bailey (n. 1910) y D. E. Harken (n. 1910), en la estenosis de la válvula mitral; T. HolmesSellors (1902-1987) y R. Brock (1903-1980) en la estenosis valvular pulmonar, y Bailey en la estenosis aórtica. Fue en el Instituto Rockefeller, en New York, donde Tuffier y A. Carrel habían realizado cirugía experimental a corazón abierto en animales antes de la Primera Guerra Mundial. Después, Carrel junto con el famoso aviador C. Lindbergh (19021974) construyeron una bomba de circulación extracorpórea que funcionó en animales (1938). A partir de aquí, tres desarrollos permitieron la cirugía a corazón abierto en humanos: el diseño de una máquina corazónpulmón que oxigenaba la sangre y mantenía su circulación a través de los grandes vasos exckuyendo al corazón; la utilización de hipotermia para disminuir las necesidades de oxígeno por los tejidos, y el descubrimiento de que la hipotermia profunda del corazón, excluido de la circulación, podía ser detenido sin deterioro significativo durante más de una hora y que después, recalentado, recuperaba el latido. Por fin, en 1953, John H. Gibbon (1903-1973) consiguió la aplicación del procedimiento en humanos. Otros nombres importantes en este desarrollo fueron J. Kirklin (n. 1917) en la Mayo Clinic y C. W. Lillehei (n 1918) en Minneapolis. La cirugía cardiaca a corazón abierto se estrenó con el reemplazamiento valvular (C. Hufnagel, 1917-1989); desde entonces y hasta 1962 se realizaron 18000 sustituciones, siendo la vávula de Starr-Edwards el tipo más utilizado. Por esas fechas, la escuela francesa (C. Dubost y A. Carpentier) propugnó la utilización de prótesis valvulares cardiacas biológicas, que no necesitan anticoagulación. La estandarización de la circulación extracorpórea permitió el abordaje de la revascularización coronaria. Tras la introducción de la arteriografía coronaria por F. M. Sones Jr (1918-1985) en la Cleveland Clinic, en 1958, el diagnóstico preciso de las oclusiones coronarias hizo posible el puenteo de la lesión (By pass coronario) mediante diferentes tipos de injertos: M. E. de Bakey (n. 1908) en EE.UU. y V. Kolesov (n. 1904) en Rusia lo hicieron posible a partir de 1964. A partir de 1988 se utilizó la arteriotomía coronaria transfemoral con balón inflable que, progresivamente y con sus numerosas variantes, está desplazando a la cirugía más agresiva.

Por lo que se refiere a la anestesiología -cómplice indispensable de la cirugía- sufrió un desarrollo parejo; la especialización anestésica permitió abordar la corrección de malformaciones congénitas en el recién nacido o el reemplazamiento de una cadera en un paciente diabético nonagenario. En los 1970s la administración profiláctica de nuevas formas de 
heparina (purificada en 1929 por C. Best (1899-1978), en Toronto) disminuyó el riesgo de trombosis y de embolismo. La posibilidad de controlar, restablecer y mantener las funciones cardiorrespiratoria y renal y con ello el equilibrio hidroelectrolítico, y el desarrollo de la alimentación parenteral, ampliaron y consolidaron el campo de la Medicina como un todo, representando las unidades de cuidados intensivos, instaladas en numerosos hospitales en los 1960s, el paradigma del clímax alcanzado. Para apreciar el impacto de la nutrición parenteral basta retroceder cincuenta años, cuando un paciente con un sistema digestivo afuncional fallecía en dos o tres semanas; de manera escandalosa, pacientes con grandes traumatismos o sépticos fallecían por inanición. El Dr. Ravdin, en Pennsylvania recibió un ayuda del Ejército para estudiar cómo mejorar la nutrición de los pacientes en situaciones de alto riesgo y, poco después, el Dr. Rhoads heredó el proyecto. Con la ayuda de sucesivas generaciones de médicos residentes ensayaron todo tipo de técnicas; pero invariablemente la administración de soluciones hiperosmolares de glucosa causaban flebitis en las venas periféricas. La solución llegó con dos logros orquestados por Rhodas. Primero, Harry Vars, un brillante bioquímico, desarrollo una solución para administración endovenosa de glucosa hipertónica que contenía proteínas y minerales, aportando la suficiente cantidad de nitrógeno y de calorías capaz de garantizar un metabolismo nitrogenado positivo y, con ello, la supervivencia del paciente. Además,
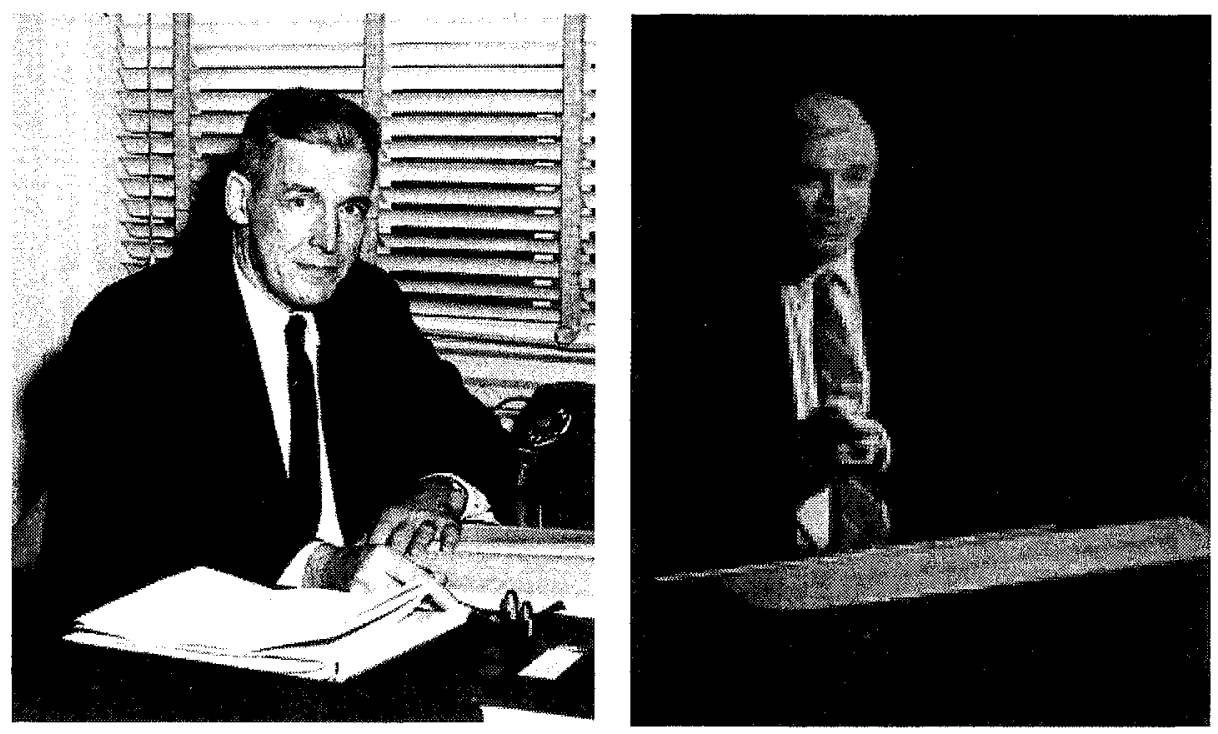

FIGURA 6. Jonathan E. Rhoads (1910-2004) y Stanley J. Dudrick (n. 1935), artífices de la alimentación parenteral total [junto con Harry M. Vars]. 
Stan Dudrick, un residente de cirugía, desarrolló una técnica simple y reproducible para la inserción de un catéter en una vena central de grueso calibre y alto flujo que, al diluir de inmediato la solución hipertónica, permitía su administración sin provocar flebitis. La denominada alimentación parenteral total permite nutrir plenamente a los pacientes durante semanas (Figura 6).

Durante casi un siglo tras los logros de Billroth, la práctica de la cirugía era una actividad no científica gobernada por las anécdotas y por los prejuicios. Poco a poco, concluida la década de 1950, los cirujanos comenzaron a introducir el método científico en el desarrollo de ensayos clínicos; ello permitió comparar los resultados de las diferentes técnicas quirúrgicas, siendo paradigmáticos los estudios que se ocuparon del tratamiento del cáncer. Desde 1900 hasta los años 1970s los cirujanos siguieron a rajatabla el concepto de William S. Halsted (Figura 7), de que el cáncer de mama se diseminaba, exclusivamente, a través de los vasos linfáticos; de ahí que el tratamiento de elección fuera la extirpación en bloque de la glándula mamaria con el tumor primitivo, de los músculos

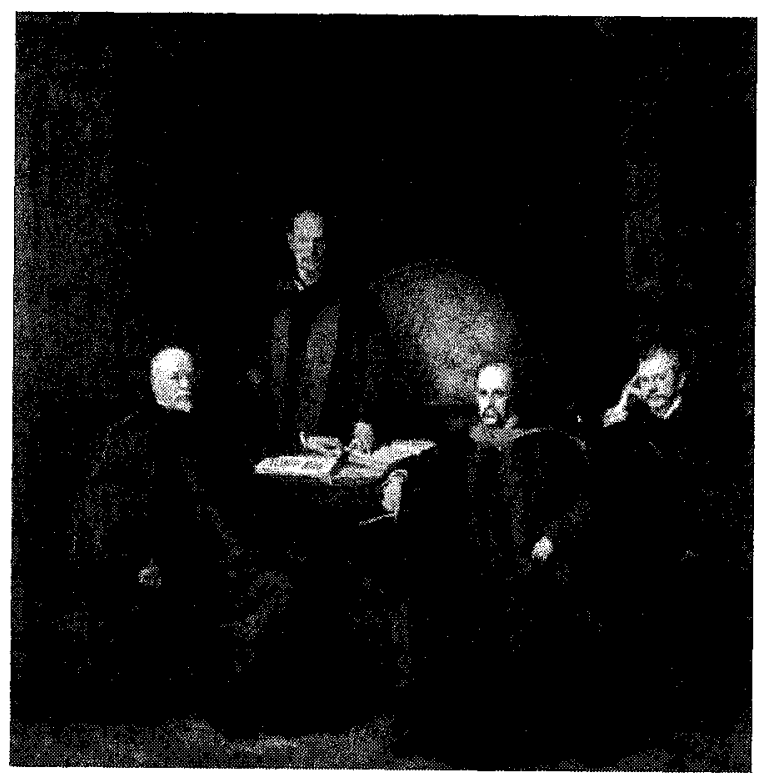

Figura 7. John Singer Sargent. Miembros de la Primera Facultad Clínica de la Johns Hopkins, 1905. En: Welch Medical Library. Johns Hopkins Medical Institutions, Office of Public Affairs, Baltimore, Maryland, EE.UU.

William Osler (1849-1919; internista), Howard A. Kelly (1858-1943; ginecólogo), William S. Halsted (1852-1922, cirujano) y William H. Wells (1850-1934; patólogo), cimentaron la más prestigiosa de las Facultades de Medicina en la Universidad Johns Hopkins. 
pectorales rebañando hasta el plano costal y de los ganglios regionales axilares (mastectomía radical). A comienzos de los 1950s, Bernard Fisher, en la Universidad de Pittsburg, se enfrentó a tal dogma proponiendo que el cáncer de mama metastatiza indiferentemente a través de vasos sanguíneos y linfáticos, de acuerdo con factores genéticos intrínsecos a las células tumorales. Para comprobar su hipótesis, Fisher inició, en 1971, un protocolo clínico para evaluar el resultado de diferentes estrategias terapéuticas del cáncer de mama invasivo; con gran sorpresa para los cirujanos, los resultados de la tumorectomía simple eran superponibles a los de la mastectomía radical. En una línea similar, años antes, Charles Huggins, de la Universidad de Chicago, había demostrado la influencia hormonal en la evolución cancerosa: los cánceres de próstata y de mama responden a la ablación de las respectivas hormonas sexuales. El cáncer de próstata responde a la castración y el de mama a la ovariectomía. Por ello, Huggins recibió el Premio Nobel de Fisiología o Medicina 1966 (Figura 8).

El broche final de la que ha sido denominada «segunda revolución» de la cirugía y que sirve de engarce con la revolución tecnológica, es la denominada cirugía de invasión mínima. En su aplicación más generalizada, los cirujanos utilizan imagen endoscópica en vez de radiológica (exoscópica) para acceder a la cavidad abdominal; pequeñas incisiones
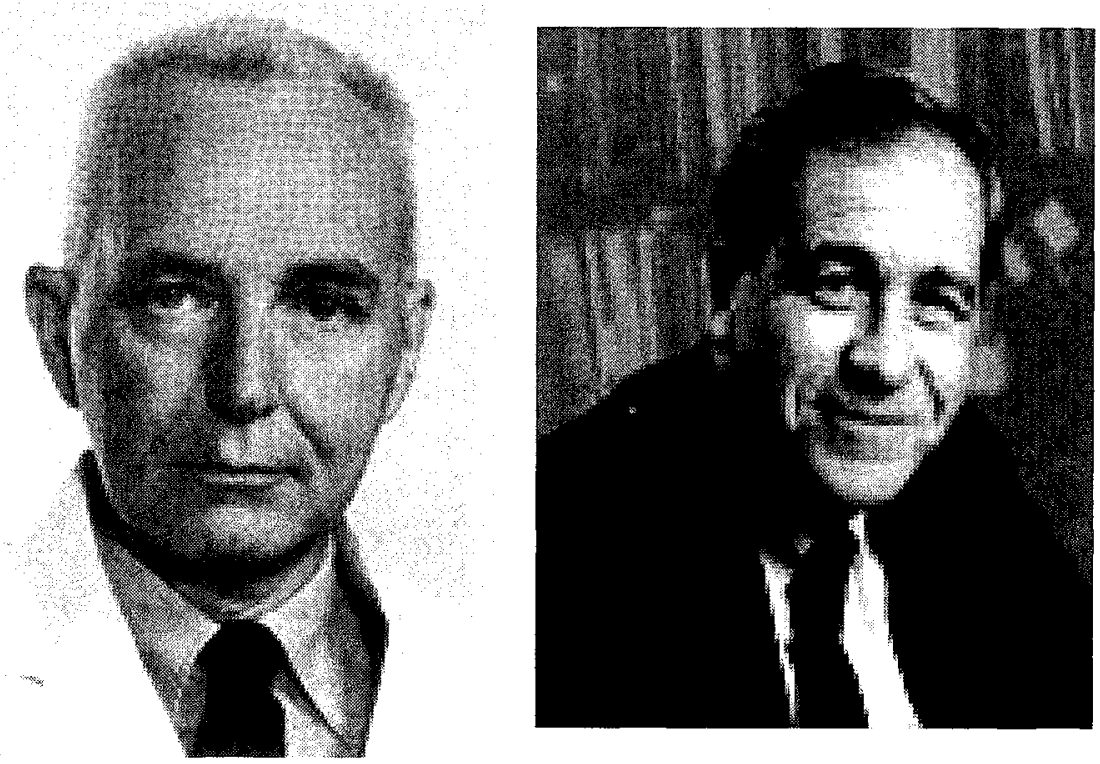

Figura 8. Charles Brenton Huggins (1901-1997), Premio Nobel 1966 "por su descubrimiento referente al tratamiento hormonal del cáncer de próstata", y Bernard Fisher (n. 1919), impulsor de los ensayos clínicos en cirugía. 
(ojales) en la pared abdominal por las que se introducen los sistemas de imagen y los artilugios miniquirúrgicos necesarios, permiten realizar intervenciones (colecistectomía, nefrectomía, ligadura de trompas, herniorrafia, etc.) que, hasta hace poco, exigían, las más de las veces, amplias laparotomías. La técnica es también aplicable a la cavidad torácica, el raquis y a las articulaciones; sistemas que en su versión actual de flexibilidad y calidad óptica, se deben al desarrollo del endoscopio flexible de fibra óptica por Harold Hopkins, en 1954. En septiembre de 1985, Eric Muhe, en Boblinge, Alemania, realizó la primera colecistectomía laparoscópica con éxito.

\section{El paradigma quirúrgico, hoy: trasplante de órganos}

La idea de componer o de recomponer cuerpos -organismos-a partir de estructuras de distintas procedencias, ha estimulado la imaginación desde tiempos remotos; así lo atestigua la mitología griega. De hecho, uno de los monstruos más emblemáticos, la Quimera, se ha erigido símbolo paradigmático de la trasplantariedad, y Cosme y Damián, patronos de la Medicina, consiguieron su milagro sobre la base de un alotrasplante. Ya en la Ilustración, los experimentos más famosos de trasplantes, previos al advenimiento de la inmunología moderna, los realizó el cirujano escocés John Hunter (1728-93), extraordinario anatomista y padre de la cirugía experimental. En 1902, un cirujano vienés nacido en Hungría, Emerich UIlman (1861-1937), publicó un trabajo sobre un trasplante renal en el perro; trabajo que sirvió de estímulo para las investigaciones de Alexis Carrel (1873-1944). Carrel, graduado en la Universidad de Lyon, trabajó en Chicago en los años 1902-4; aquí aplicó los principios de la cirugía vascular al trasplante, asentando los principios técnicos de este. Por ello, recibió el Premio Nobel de Fisiología o Medicina en 1912 (Figura 9$)$.

Junto con la técnica quirúrgica - la Cirugía reclama el trasplante como suyo y tal vez sea su rama más importante -, el otro componente esencial es inmunológico. Los fundamentos científicos de la inmunología se establecieron a las puertas del siglo XX. En 1898, Jules J. B. V. Bordet (1870-1961) reconoció la lisis de los eritrocitos extraños tras la transfusión de sangre y, en 1901, Karl Landsteiner (1868-1943) inició el estudio de los grupos sanguíneos del sistema $\mathrm{ABO}$ en los eritrocitos. A principios de los años 1920s, diferentes estudios sobre el rechazo del injerto soportaron el trabajo clásico de Peter Gorer, que condujo a la formulación de la teoría de la especificidad antigénica tisular de los dife- 


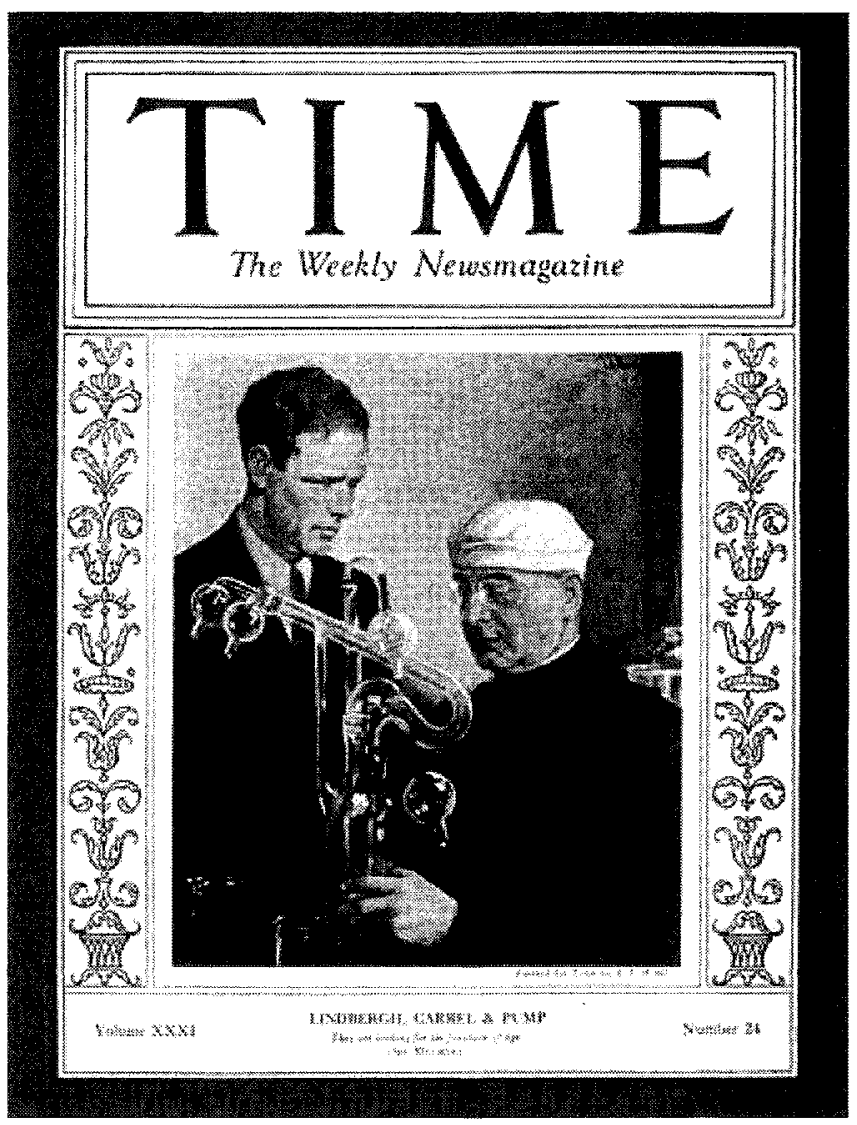

FIGURA 9. Alexis Carrel (1873-1944), Premio Nobel 1912 «en reconocimiento por su trabajo sobre la sutura vascular y el trasplante de vasos y de órganos", y Charles Lindbergh (1902-1974). Juntos desarrollaron una bomba oxigenadora con la que Carrel abordó el trasplante experimental de corazón y de riñón.

rentes individuos. Y en 1943, Peter B. Medawar (1915-1987) et al. demostraron que el organismo receptor destruye el tejido injertado a través de un mecanismo inmunológico que involucra una respuesta celular mediada por los linfocitos y otra respuesta humoral dependiente de los anticuerpos circulantes. Más aún, la destrucción del injerto establece una memoria en los leucocitos que reconocerán, de inmediato, un nuevo injerto procedente del mismo donante y al que destruirán más expeditivamente que al primero.

La unión definitiva entre cirugía e inmunología tuvo lugar cuando el tipaje inmunológico fue utilizado, por vez primera, en la selección de un donante. Ello tuvo lugar en Boston, en 1954; lo realizó el equipo dirigido 


\section{De la trepanación a la cirugía virtual}

por Joseph E. Murray en un trasplante renal entre gemelos idénticos (Figura 10). Por último, la aplicación sistemática de inmunosupresión para controlar el rechazo del injerto completó el esquema básico del trasplante. Hoy, la supervivencia global de los trasplantes se sitúa en el 70-80\% al primer año y en el $50 \%$ a los cinco años; hay pacientes que aún viven tras 30 años de haber sido trasplantados. Hoy, más de 100000 trasplantes realizados y treinta y cinco años de aplicación ininterrumpida de una técnica son razones más que suficientes para que sea aceptada como rutinaria; tal es el caso de los alotrasplantes de riñón, corazón, hígado, piel o hueso. El tiempo juega, de igual modo, a favor de los trasplantes de pulmón, páncreas, segmentos intestinales o multiorgánicos. El resultado es que el incremento en la demanda va muy delante de la disponibilidad de órganos; el equilibrio sólo podrá lograrse mediante la combinación de medidas educativas, incentivación o medidas legales, que lleguen a permitir la recuperación de todo órgano médicamente aceptable.

Los autoinjertos de piel fueron preconizados en 1869 por J. L. Reverdin (1842-1929) en Ginebra y sistematizados por C. Tiersch (1822-1895) en Leipzig, en 1872. Se aplicaron al tratamiento de úlceras, quemaduras y para reparar defectos cutáneos secundarios a la extirpación de tejidos subyacentes. El injerto de piel marcó el comienzo de la cirugía plástica y

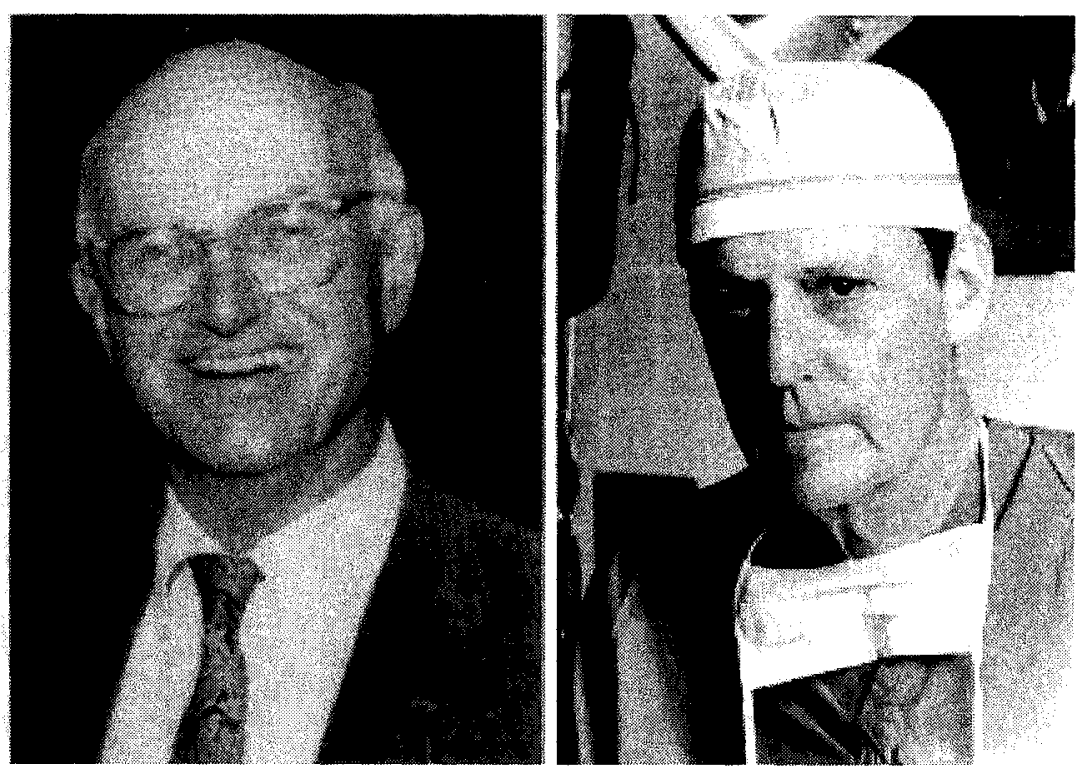

Figura 10. Joseph E. Murray (n. 1919) - compartió [con E. Donnall Thomas (n. 1920)] el Premio Nobel 1990 «por sus descubrimientos referidos al trasplante de órganos y de células en el tratamiento de la enfermedad humana» -, y Thomas E. Starzl (n. 1926), verdadero impulsor de los trasplantes de órganos. 
reconstructora. Los aloinjertos se intentaron a partir de 1880 , utilizando piel de cadáveres o de miembros amputados, siendo el resultado descorazonador. Un poco más tarde comenzó el trasplante de órganos vivos: Gluck, en Berlin, trasplantó hueso descalcificado (1890) y E. Ullmann (1861-1937), en Viena, experimentó el autotrasplante heterotópico de segmentos intestinales (1901).

Con el antecedente de la sutura vascular (fístula de Eck-Pavlov) y del trabajo de Carrel (1902), que demostró la viabilidad de los vasos injertados tras varios días en condiciones de laboratorio definidas de que, los autoinjertos venosos fueron empleados por primera vez en clínica por J. G. Capdevilla (1876-1964) en Madrid (1906) y por E. Lexer (1867-1937) en Königsberg (1907); por su parte, la técnica del trasplante renal experimental en animales fue perfeccionándose en Viena, Berlin, Lyon y New York; Mathieu Jaboulay, un pionero de la cirugía vascular, y E. Unger (1875-1938) en Berlin, llevaron a cabo trasplantes renales en clínica en 1906 y en 1910, respectivamente; el último intentó un xenotrasplante utilizando el riñón de un mono, lo que también se había intentado con el páncreas en 1894. Dado el rechazo de los aloinjertos, el trasplante de órganos fue relegado hasta después de la Segunda Guerra Mundial.

El interés por los trasplantes fue retomado por el desarrollo del riñón artificial, una máquina inventada por el holandés W. Kolff (n 1911). Los pacientes con insuficiencia renal crónica dependían, por vida, de las sesiones de hemodiálisis; ello motivó retomar los programas de trasplante renal. El primer programa desarrollado con éxito, sobre la base de utilizar riñones de familiares próximos, lo dirigió J. Murray, en Boston, en los primeros años de los 1950s.

Mientras tanto, el concepto de la naturaleza inmunológica del rechazo del órgano alotrasplantado, formulado antes de la Primera Guerra Mundial, fue reelaborado y sometido a contrastación experimental por M. Burnet (1899-1985) y P. B. Medawar (1915-1987). En 1953, Medawar describió la posibilidad de inducir una tolerancia, pero los alo- y los xenotrasplantes realizados en EE.UU. y en Francia, incluso tras la irradiación corporal total con rayos $\mathrm{X}$ y el tratamiento previo con cortisona, fracasaron. Alrededor de 1960s se utilizaron los primeros fármacos inmunosupresores (6-mercaptopurina y azatioprina), pero su toxicidad y efectos colaterales no eran controlados. A principios de la década de 1980s se introdujo la ciclosporina -descubierta en 1972 por Jean Borel (n. 1933)-, fármaco que cambió el panorama del trasplante clínico. A la vez, se fueron solucionando los problemas de preservación de los órganos donados, lo que permitió su transporte; poco después, el Eurotrasplante, una organización centrada en Leiden, hizo del alotrasplan- 
te renal el tratamiento de elección de la insuficiencia renal crónica en Europa.

Por su parte, la desaparición a la barrera ética contra el trasplante cardiaco fue provocada por Christiaan Barnard (1922-2001) quién, el 27 de diciembre de 1967, en el hospital universitario de Cape Town, en Sudáfrica, realizó el primer alotrasplante en clínica humana. Cinco años después, 56 equipos en todo el mundo habían practicado 180 alotrasplantes de corazón. La mayoría de estos equipos abandonaron la carrera; ello, debido a los graves problemas planteados por el rechazo del órgano. Años después, Norman Shumway (n 1923), en Stanford, consiguió desarrollar las condiciones metodológicas para llevar a cabo un programa de trasplante cardiaco que ha permitió realizar, hasta comienzos de la década de los, 1990s, más de 15000 trasplantes cardiacos en todo el mundo.

En cuanto al trasplante hepático, Thomas E. Starzl (n 1926) puso en marcha el primer programa de trasplante en 1968, en Denver; Starzl, de la mano de Paul Terasaki, también introdujo las pruebas de histocompatibilidad. La historia del trasplante de pulmón se remonta a los 1960s, aunque su sistematización se debe a J. Copper, en Toronto, quién culminó con éxito una serie entre 1977 y 1982. Los trasplantes intestinales y pancreáticos van abriéndose camino, al igual que los trasplantes multiorgánicos. Por último, los trasplantes de córnea, cartílago, hueso, cadena auditiva y válvulas cardiacas, son rutinarios, y el trasplante de médula ósea ha alcanzado la condición de tratamiento clínico médico.

El trasplante de órganos es el ejemplo más típico de la cirugía de reemplazamiento que caracteriza las tres últimas décadas. Numerosas prótesis se han convertido en tratamientos de rutina, mientras que el corazón artificial está, aún, en fase experimental. Los órganos artificiales ilustran, de manera particular, la naturaleza multidisciplinar de la cirugía de este tercer periodo; cirugía que exige la colaboración no solo de las ciencias experimentales clásicas, sino de la electrónica, de la ciencia de los nuevos materiales y de la ingeniería.

El trasplante de órganos se acompaña de importantes discusiones respecto a condicionantes médicos generales, éticos y legales: la definición de muerte cerebral que faculta la donación de órganos - aunque comienza a abrirse paso la donación a partir de «cadáveres» -, la aceptación por la ciudadanía y por los médicos en general, la situación de los pacientes que esperan un trasplante, la equidad en la distribución de los órganos disponibles, son algunos de los temas más manidos. El trasplante señala la punta del iceberg de la clase de temas que hacen progresar el contexto médico-quirúrgico como un todo. 


\section{El triunfo de la tecnología: hacia la medicina nintendo y la cirugía virtual}

No cabe duda de que pocos aspectos de nuestras vidas han cambiado tan profundamente en los últimos años como aquellos que se ocupan de la atención de la salud; ello es debido, en gran medida, al impresionante desarrollo tecnológico. Tecnología que, en gran parte, ha mejorado la calidad de la atención sanitaria; logro, sin embargo, que ha resultado costoso. Se oye y se lee, con frecuencia, que los sistemas de atención sanitaria en los países industrializados se encuentran en una situación de crisis. Cada año incrementa la demanda de servicios sanitarios y se reaviva el debate permanente de lo que los presupuestos y los ciudadanos están dispuestos a pagar por ello. No es un problema de fácil solución, pues pertenece a aquellos que no tienen soluciones técnicas sino políticas y socioculturales.

Para explicar por qué los costes de los servicios sanitarios son tan difíciles de contener se han apuntado varias razones; entre ellas, la tecnología aparece en primer lugar. La tecnología, que ha seducido a los profesionales, a los medios de comunicación y a los usuarios del sistema, es cara. El uso popular de la palabra tecnología - aparatos y procedimientos que operan sobre la base de la ciencia más avanzada, en contraste con lo que se supone que es el arte de la medicina - dista de la versión formal del término: los medicamentos, aparatos y procedimientos médicos y quirúrgicos usados en la atención sanitaria, y los sistemas organizativos y de soporte en los que se proporciona tal atención.

De acuerdo con la definición popular, la tecnología diagnóstica contempla la utilización de sofisticados aparatos, de compuestos radiactivos y de electrónica, y cómo llegar a los diagnósticos empleando computadoras; ello, de manera distinta a la tradicional de hacer la medicina a partir de la historia clínica, la palpación y la auscultación mediante un fonendoscopio. De manera similar, la tecnología terapéutica se asocia a complejas intervenciones quirúrgicas como el trasplante de órganos, a la implantación de complicados artilugios como una neuroprótesis o a procedimientos que requieren grandes máquinas como la oncorradioterapia o la litotricia ultrasónica. Todo ello distingue a la tecnología de lo que se consideran actuaciones pasadas de moda, sin duda más económicas como el reposo, una tisana o una simple aspirina. La tecnología se percibe como algo muy complejo y, sobre todo, más caro; característica que se ha impuesto incluso en el lenguaje técnico, pues se conoce como «alta tecnología médica» o «big ticket technology» a los modernos sistemas electromecánicos cuya factura hace tambalear los presupuestos. 
Con todo, la percepción de la tecnología es cambiante; el estetoscopio de Laenec o la aplicación de la vacuna por Jenner supusieron «alta tecnología» cuando se introdujeron en la práctica médica. Así, en relación con su utilización en los servicios sanitarios, las características de la tecnología son la novedad frente a lo convencional, la complejidad científica frente a la simplicidad del sentido común y el alto coste frente a la accesibilidad. Sin embargo, hay una trampa semántica en todo ello; casi toda la medicina actual se basa en tecnologías que no existían hace cincuenta años. Peyorativamente se denomina «medicina tecnológica» $y$, a la vez, se imputa a la tecnología la dificultad para controlar el sistema sanitario.

Hace cincuenta años un bloqueo cardiaco en un paciente entrado en años conducía irremediablemente a la muerte; hoy, el implante de un marcapaso cardiaco (aprox. $9100 €$ ) soluciona el problema. En los años que siguieron a la Segunda Guerra Mundial, el tratamiento del fracaso renal crónico consistía en aliviar al enfermo hasta su fallecimiento; en la actualidad, el trasplante renal (aprox.45000 €) reintegra al paciente a una vida social activa. Por su parte, la revascularización miocárdica o «bypass» coronario (aprox. $24000 €$ ) es una práctica rutinaria, algo impensable en aquellas fechas. Hasta aquí tres ejemplos, pero la «carta» es mucho más extensa: los nuevos materiales permiten reemplazar caderas o rodillas dolorosas y lentes oculares opacificadas; la radiación de alta energía y los nuevos fármacos controlan numerosos cánceres, y combinaciones de nuevos compuestos han hecho del sida una enfermedad crónica. En nuestros días, en vez de morir ahorrando, los pacientes viven física, psíquica y socialmente por un precio que la sociedad debe asumir. El porcentaje de los Presupuestos destinado a financiar los sistemas de salud incrementa en proporción al éxito de la innovación tecnológica, pero las tecnologías sanitarias deben juzgarse, entre otros factores y ante todo, por los beneficios que aportan a los individuos y a la sociedad.

Por otro lado, el contrato médico, desde el nacimiento de la medicina, se ha establecido sobre las bases de la curiosidad diagnóstica (lado del médico) y la expectativa terapéutica (lado del enfermo). El genio hipocrático insertó el pronóstico entre ambas; en toda medicina racional, cualquier terapia eficaz deberá utilizarse, solamente, cuando el médico pueda anticipar - con las restricciones obvias - el curso de la enfermedad con o sin tratamiento. El pronóstico hipocrático se enseñaba como una habilidad clínica basada en observaciones empíricas y como una obligación ética. Estas ancianas reglas han guiado el contrato médico durante siglos.

En el momento actual, la importancia ética del pronóstico ha variado. Muchas intervenciones terapéuticas pueden hoy emplearse en escenarios 
clínicos donde nada podía hacerse pocos años atrás. Ahora, los médicos no admiten que una enfermedad pueda haber vencido a un paciente $y$ aplican, a menudo, medidas extraordinarias ante un pronóstico más que incierto; medidas que, en ocasiones, cruzan la frontera de lo razonable. El problema de los tratamientos inútiles, en cierto sentido erróneos al no ofrecer beneficio terapéutico alguno para el paciente, exigen un debate que revise las relaciones médico-enfermo; es necesario que la sociedad recupere el sentido común y la realidad en la percepción que tiene de las posibilidades de la medicina. Pero ese debate se ve influido por poderosos condicionantes culturales, legales y políticos. El ser humano se resiste a morir; se considera algo anormal, patológico, la muerte de una persona. El ser humano acepta con dificultad su humanidad; la ciencia le ha convencido de que es posible vencer a la muerte. Esa misma cultura tecnológica hace que el médico acepte con dificultad los límites de su poder; la muerte representa su fracaso. Sin embargo, el compromiso de la medicina no debe ser con la vida en cualquier forma, sino con el enfermo que sufre; ello lleva implícito que todos los pacientes, eventualmente, pueden morir sin que ello represente un fracaso médico.

El estetoscopio, introducido en la clínica por René Laënec (1781-1826) en 1818, influyó en la organización de la propia medicina, en su práctica y en su enseñanza. El dominio de los sonidos patológicos y su asociación con las lesiones anatómicas exigían el acceso a un gran número de pacientes, la presencia de colegas con quienes discutir los hallazgos y facilidades para realizar las correspondientes autopsias donde cotejarlos. Todo ello solo podía conjuntarse en el hospital, institución que quedó consagrada como el lugar idóneo para la práctica y la enseñanza de la medicina. Laënec escribió: «... solamente en el hospital es posible adquirir, completar y perfeccionar la práctica y el hábito de este nuevo arte de diagnóstico».

Los logros diagnósticos alcanzados por el estetoscopio y la creciente orientación de la medicina hacia un concepto anatómico de la enfermedad, crearon el clima propicio para que los médicos se lanzaran a la búsqueda de tecnologías que les permitieran el acceso a otras partes del cuerpo humano. El resultado fue una serie de innovaciones desarrolladas en la segunda mitad del siglo XIX: el oftalmoscopio (1850), el laringoscopio (1857) y una serie de espéculos disponibles en los 1860s que permitieron el examen de la vejiga, el estómago, el recto o la vagina.

A finales del siglo XIX los doctores disfrutaban de su poder y prestigio como escudriñadores y analistas de la evidencia física. Pero era necesario dar el salto desde las propiedades cualitativas del estetoscopio a la cuantificación. El instrumento que inició la transición desde lo cualitati- 
vo a lo cuantitativo fue el termómetro que, aunque inventado por Galileo (1564-1642) a finales del sXVI, no tuvo aplicación clínica alguna. En el año 1868, el médico alemán Carl R. A. Wunderlich (1815-1877) publicó «La Temperatura en la Enfermedad: un Manual de Termometría Médica», obra que recopilaba las observaciones sobre la evolución febril en miles de pacientes estableciendo dos principios básicos: en las personas sanas la temperatura se mantiene constante dentro de unos estrechos límites, y la evolución febril en los pacientes es una referencia importante en el seguimiento de la enfermedad. Wunderlich comparó los hallazgos termométricos con los derivados de la percusión y de la auscultación, concluyendo que la termometría tenía la ventaja sobre las investigaciones acústicas de que sus resultados podían expresarse en números.

Las diferencias que Wunderlich señaló entre el carácter de la evidencia proporcionada por el termómetro y la conseguida por diferentes técnicas de exploración física como la auscultación, fueron reelaboradas por otros; entre ellos, por Edward Seguin (1843-1898), un médico americano que escribió un tratado sobre el termómetro. En los 1870s, Seguin clasificó las técnicas diagnósticas en dos grupos: de «diagnóstico físico», como el estetoscopio y el oftalmoscopio que representaban simples accesorios que ampliaban los sentidos, y de "diagnóstico positivo», como el termómetro y el esfigmógrafo que sustituían a los sentidos proporcionando de manera automática resultados percibidos matemáticamente e independientes de los sentidos: «lo que dice el termómetro no puede contradecirse». El esfigmógrafo, desarrollado por Etienne Jules Marey (1830-1904) para monitorizar los latidos arteriales, fue el más relevante de los instrumentos de aquella época, y fue el antecedente de los aparatos electrónicos del siglo XX como el electrocardiógrafo. Por otro lado, Marey, Seguin y Wunderlich insistieron en la necesidad de recoger, de manera sistematizada, los diferentes datos derivados de la atención médica del enfermo; actitud que fue el origen de las hojas de recogida de datos impuestas hoy, como actividad rutinaria, en la práctica hospitalaria.

En cualquier caso, la innovación tecnológica que mayor impacto ha tenido en la historia de la medicina han sido los rayos $\mathrm{X}$. Cuando los detectó, hace ahora poco más de cien años, Wilhelm Conrad Röntgen (1845-1923) se refirió a ellos como una nueva clase de rayos. Pocos descubrimientos han abierto tantos caminos. De todas las propiedades de los rayos X, su capacidad de hacer visible lo invisible fue, sin duda, la más fascinante; por ello, durante años, la temática principal de las investigaciones se refirió a las imágenes anatómicas. Conforme creció el conocimiento de tal radiación se expandió el campo de sus aplicaciones, que incluyó el estudio de la composición y de la estructura de la materia y la estructura y el 
desarrollo del universo. En el año 1914, Max von Laue (1879-1960) recibía el Premio Nobel de Física (P. N. Física) por su descubrimiento de la difracción de los rayos X por los cristales, hecho que abrió las puertas al desarrollo del análisis de las estructuras cristalinas mediante la espectrometría de rayos X, estudios por los que William Henry Bragg (18621942) y su hijo William Lawrence Bragg (1890-1971) recibieron el P. N. Física al año siguiente. El estudio de los rayos $\mathrm{X}$ también proporcionó las bases para el modelo atómico desarrollado por Ernest Rutherford (18711937; P. N. Química, 1908) y por Niels Bohr (1885-1962; P. N. Física, 1922). Años después, Dorothy Crowfoot Hodgkin (1910-1994) recibió el P. N. Química en 1964 por sus determinaciones de las estructuras de importantes sustancias bioquímicas mediante técnicas de rayos X. Por su parte, el estudio de los rayos $\mathrm{X}$ emitidos por lejanos objetos estelares se ha establecido como una especialidad de la astronomía. Además, los rayos X representan una herramienta útil en metalurgia, geología, arqueología y arte, y tuvieron un lugar destacado en la Strategic Defense Iniciative («guerra de las galaxias»). Por último, la radiobiología (estudio del efecto de las radiaciones electromagnéticas, en especial las ionizantes, sobre los organismos vivos y sus tejidos), que tuvo su origen en las investigaciones con rayos $\mathrm{X}$, facilitó las bases científicas de la radioterapia (tratamiento de la enfermedad, en especial del cáncer, mediante radiación ionizante) y de la radioprotección.

La imagen incruenta del interior corporal, producto de la aplicación del descubrimiento de Röntgen, que le valió el P. N. Física de 1901, significó una verdadera revolución conceptual y uno de los acontecimientos más impactantes de la historia de la ciencia en la conciencia del público en general. La imagen de la mano de Bertha Röntgen -una de las más insistentemente reproducidas-, daría origen a una nueva era, en continua evolución, de la Medicina. Sin embargo, la aplicación del diagnóstico radiológico no fue la esperada, pues no todo fue optimismo y alabanza en torno al nuevo método. Hubo que esperar al año 1914 para que la prometedora técnica despegase. Ello por dos motivos; la Gran Guerra despertó el interés en la detección de las fracturas óseas y, en esa fecha, se fabricó el primer tubo catódico moderno. Por su parte, el periodo entre las dos Guerras Mundiales aseguró la utilización regular de los rayos X en la detección de la tuberculosis pulmonar, aunque en esta época los radiólogos no eran más que fotógrafos de rayos X. No fue infrecuente que los médicos clínicos consideraron el diagnóstico radiológico como una intrusión, a la vez que despreciaron la estática de una fotografía por rayos $\mathrm{X}$ frente a la dinámica de la auscultación. Ello no fue óbice para que Arthur Holly Compton (P. N. Física 1927, por el descubrimiento del efecto 
que lleva su nombre) sentenciara años después, en 1957, que «durante ese periodo los rayos $X$ habian salvado tantas vidas como las que se habían perdido entre las dos Guerras».

La ingeniería médica es una actividad emergente que asocia humanos y máquinas con el propósito de hacer mejor ciertas operaciones que si las realizaran cada uno de ellos por separado. Para los médicos, esta asociación es importante porque ofrece posibilidades de mejorar la eficacia y la seguridad de procedimientos clínicos existentes y de desarrollar otros nuevos que no pueden llevarse a cabo de otra manera. Para los tecnólogos, la asociación ofrece el reto de llevar a la práctica ciertas aplicaciones mediante operadores articulados. A efectos de diseñar asociaciones de este tipo, que involucran capacidades complementarias, es necesario considerar los puntos fuertes y débiles de cada parte. Los cirujanos tienen muchas habilidades; tienen gran destreza y están bien entrenados para sacar partido de referencias táctiles y visuales. Se adaptan y pueden realizar sus habilidades en un amplio intervalo de escalas geométricas. Mediante un control «juicioso», comprenden lo que hacen y lo que sucede durante el acto quirúrgico y utilizan su destreza, sus sentidos y su experiencia para ejecutar el procedimiento adecuado. Pueden analizar su propio rendimiento y aplicar las lecciones aprendidas, esto es, progresan con la práctica.

Sin embargo, los cirujanos tienen sus limitaciones. No son geométricamente precisos; en otras palabras, no pueden colocar con facilidad un instrumento determinado en una localización exacta y luego moverlo a lo largo de una trayectoria definida, ni tampoco son muy buenos a la hora de ejercer con exactitud una fuerza predefinida en una dirección determinada. No toleran bien la radiación ionizante. Son torpes si se les exige trabajar en espacios confinados durante mucho tiempo. Sufren de imperceptibles tremores en sus manos que limitan su capacidad para operar sobre estructuras muy delicadas. Se cansan y, con ello, cometen errores. Envejecen y pierden su habilidad. Desafortunadamente muchas de esas limitaciones afectan la eficacia de ciertos procedimientos quirúrgicos, especialmente en aquellos casos donde se requiere una gran precisión geométrica.

Afortunadamente, las máquinas tienen habilidades complementarias que pueden paliar algunos de los defectos de los cirujanos. Las máquinas son muy precisas e incansables, pudiendo repetir, sin limitación alguna, posiciones y trayectorias; reaccionan con rapidez adecuando instantáneamente la fuerza a la resistencia cambiante de las estructuras que encuentran en su camino. Pueden miniaturizarse para operar en espacios muy confinados y pueden resistir dosis elevadas de radiación ionizante. A la vista de todo ello, los robots se perfilan como las mejores herramientas quirúrgicas. Herramientas que no son una amenaza para reem- 
plazar a los cirujanos, pero pueden ayudarlos a hacerlo mejor. A pesar del esfuerzo realizado, la asistencia automática -segura, fiable y efectiva- en cirugía no se ha desarrollado con la velocidad anticipada.

Otro aspecto de la robótica médica es el diseño de manos robóticas sensitivas que sean capaces de restaurar la funcionalidad manual a personas que la hayan perdido: ello de la mano, valga la redundancia, de una especialidad emergente: háptica o ingeniería de la función manual. La posibilidad de prótesis de miembros cuyos sensores puedan percibir y trasmitir información táctil a los nervios sensoriales intactos de la raíz del miembro amputado, es uno de los objetivos finales de la robótica. Microrrobótica, realidad virtual, comunicaciones integrales o globales, imagen tridimensional y cirugía por telepresencia, son los ingredientes claves del programa denominado Surgery 2001, de la Advanced Research Projects Agency del Pentágono. Todo ello exige replanteamientos conceptuales, docentes, formativos, prácticos y asistenciales.

Un tema relevante es la sinergia que pueda lograrse entre los métodos computacionales para la planificación prequirúrgica y la mejor capacitación para ejecutar los planes previstos. Para que los sistemas computacionales tengan valor es esencial que el cirujano sea capaz de llevar a cabo la estrategia planificada. Si se pretende la simulación cualitativa preoperatoria, debe ser posible que el cirujano ensaye una y otra vez y lleve los resultados al quirófano o los almacene en su cabeza. La utilidad de tal simulación descansa en que el sistema permita el perfeccionamiento quirúrgico clínico, proporcionando al cirujano un dispositivo interactivo en tiempo real. Si el planteamiento exige información cuantitativa -forma y posición de un tumor o posiciones y orientaciones de los fragmentos óseos en una osteosíntesis- el objetivo será conseguir la precisión geométrica intraoperatoria.

Como cualquier campo técnico que todavía no está bien estructurado, existe a menudo cierta redundancia entre los conceptos que lo componen y las subdisciplinas que lo integran. No hay acuerdo sobre cómo debe denominarse: cirugía asistida por computadora, quirobótica dirigida por imagen, robótica médica, medicina integrada por computadora, cirugía por informatización intensiva o cirugía integrada por computadora. La última denominación enfatiza la integración de planteamiento y análisis prequirúrgicos, de sistemas de ejecución quirúrgica basados en computadora y de seguimiento y control de calidad postquirúrgicos. Sin embargo, la denominación es menos importante que la realidad emergente de estos nuevos sistemas.

La medicina virtual es un aspecto fascinante de la realidad virtual. Un primer paso hacia las posibilidades venideras lo representa un atlas 


\section{De la trepanación a la cirugía virtual}

anatómico en CD-ROM; por su parte, un cuerpo humano digitalizado está a punto de ser vertido en la red de fibra óptica de las universidades americanas. Algo más futurista es un modelo 3D de cerebro, loncheable, que han desarrollado un hospital de Boston y General Electric; con la ayuda de unas gafas estereoscópicas y la ayuda de un ratón puede diseccionarse tal cerebro como si se tratara de una preparación anatómica en la sala de disección. Un residente en cirugía que se ejercita en cadáveres reales no puede repetir un procedimiento quirúrgico si se equivoca; los órganos no pueden reconstruirse una vez dañados. Además, la curva de aprendizaje de un especialista continúa durante muchos años tras lograr su titulación; se necesitan varios cientos de intervenciones in vivo para lograr una eficacia comprobada. Una alternativa es que los futuros cirujanos se entrenen de manera similar a cómo lo hacen los pilotos de aeronaves. La investigación de simuladores corporales para cirugía - algo parecido a los simuladores virtuales de vuelo - ha dado sus pasos iniciales; existen en fase experimental una pierna virtual para entrenamiento en traumatología y un cuerpo virtual para cirugía abdominal. En el abdomen virtual se encuentran todas las vísceras y en el quirófano, también virtual, todo el instrumental necesario para la laparotomía y la intervención programada. El cirujano, enfundado en su casco de inmersión virtual y sus guantes activos, puede repetir tantas veces como desee la intervención elegida; sintiendo en sus manos la impresión que produce el bisturí cuando corta el tejido, y viendo imágenes compuestas que le permitan valorar lo que hay detrás de la sangre y de las superficies opacas. ¿Cuanto tiempo llevará que esa visión madure? Los principales retos no son técnicos; los conceptuales y los relacionados con las competencias de las actuales especialidades serán más difíciles de derribar (Figura 11).

La historia de los sistemas de atención sanitaria de diferentes países, en las últimas tres o cuatro décadas, revela una preocupación constante por tres problemas difíciles de resolver: la distribución no homogénea de los recursos sanitarios, el inadecuado acceso a esos recursos por parte de determinados segmentos de la población y un imparable incremento del coste de la atención sanitaria. A esa preocupación deben añadirse exigencias ajenas derivadas de los contextos aeroespacial y militar. La telemedicina proporciona una respuesta polivalente a todos los problemas y exigencias señaladas; ello, mediante la aplicación de una combinación de tecnologías innovadoras de información, en especial telecomunicación audio/video bidireccionales e interactivas, telemetría y computadoras para garantizar diferentes servicios médicos a pacientes remotos, y para facilitar el intercambio de información entre los médicos, en especial entre los 


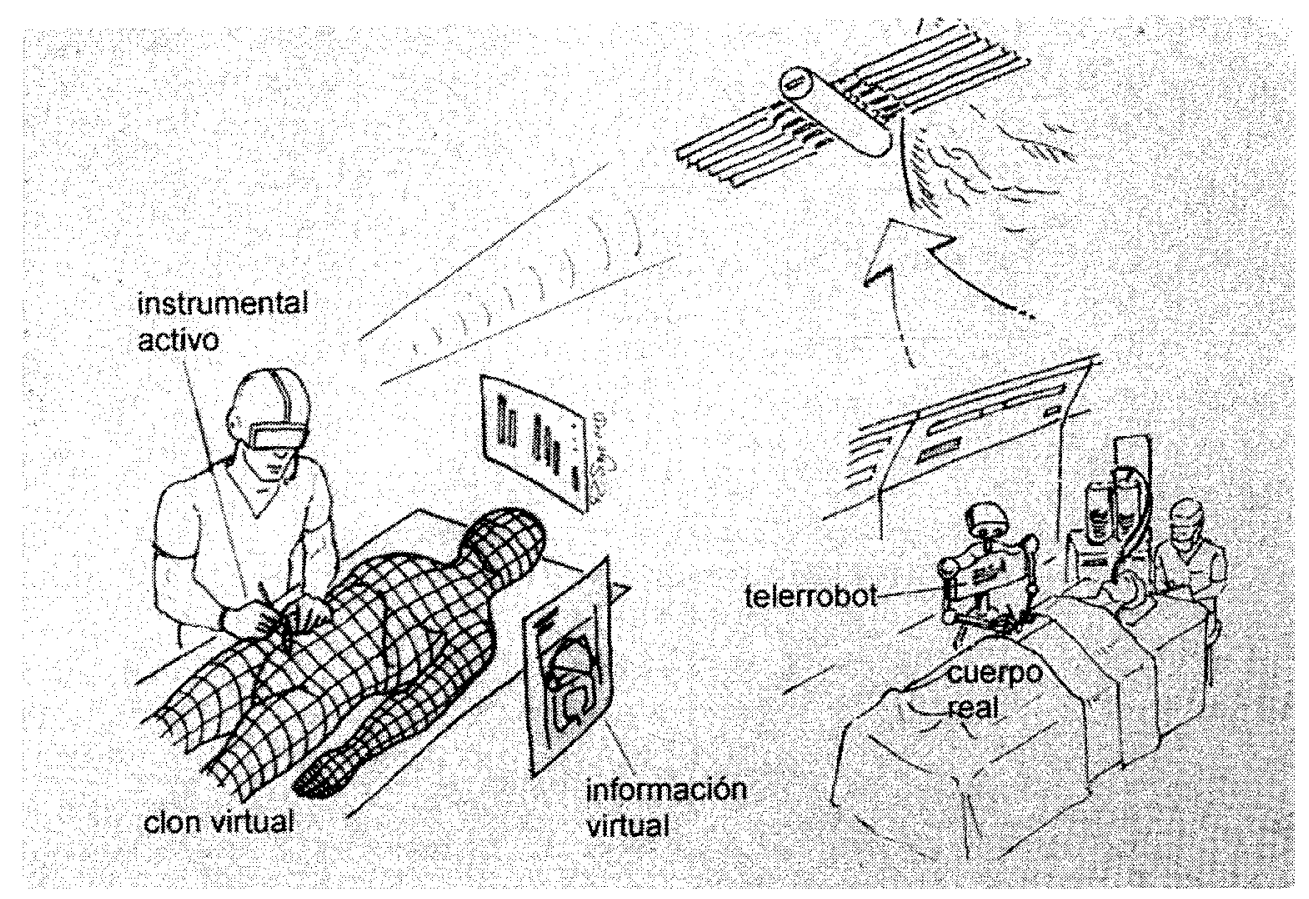

Figura 11. Cirugía virtual + telemedicina $=$ medicina nintendo.

de atención primaria y fundamentalmente los del área rural, y los diferentes especialistas de los centros asistenciales terciarios (hospitales). Por su parte, un sistema de telemedicina es un centro médico, típicamente regional, que ofrece servicios sanitarios integrados a una población definida mediante la utilización de las telecomunicaciones y las computadoras.

Sobre la base de la amplitud de la descripción aportada, podría aceptarse que la telemedicina comenzó con el intercambio de información entre los médicos o la primera vez que un médico dio un consejo a un paciente a través de un teléfono. Sin embargo, la telemedicina, tal como se entiende en el momento actual, inició su andadura a finales de la década de $1960 \mathrm{~s}$, cuando se inauguró una consulta psiquiátrica a través de un circuito cerrado de televisión entre el Instituto de Psiquiatría de Nebraska y un sanatorio psiquiátrico en una región alejada de ese estado norteamericano. Sin embargo, esa primera generación telemédica quedó abortada; ello porque las autopistas de la información necesarias estaban aún por llegar, por la inexperiencia informática y computacional de los médicos que participaron en esas primeras experiencias y porque las agencias financiadoras, ante la escasez de resul- 
tados, se desanimaron prematuramente. La primera generación de proyectos de telemedicina demostró la necesidad de prestar más atención y de reevaluar con más rigor las complejas dimensiones tecnológicas, sociales, culturales y organizativas, que acompañan a la introducción de la telemedicina.

A pesar de una historia que tiene ya cuarenta años, el progreso y la difusión de la telemedicina se caracterizan por su lentitud y limitación. Los proyectos de telemedicina -telerradiología, teleoncología y telepsiquiatríaque se iniciaron a finales de la década de 1980s representan la segunda generación telemédica; proyectos que luchan por romper las resistencias, reales o percibidas, a su desarrollo. Las grandes oportunidades de la telemedicina para mejorar el diagnóstico, la terapéutica y la educación médica son, a la vez, grandes retos; los principales se refieren al problema de la «última milla»; esto es, la capacidad de comunicación en las mismas consultas médicas y, en último lugar, en la casa de los pacientes. Están realizándose experiencias piloto mediante la instalación de pequeñas estaciones automáticas de alarma en los hogares de pacientes con enfermedades crónicas que los conectan, a través de un circuito de televisión, con una clínica. Diferentes instrumentos simples de telediagnóstico - estetoscopio, otoscopio, espirómetro, electrocardiógrafo, etc.- pueden ser manejados por el paciente bajo la supervisión remota de una enfermera o de un médico. Ello proporciona, en tiempo real, el diagnóstico y el tratamiento precoz en situaciones límite en las que el traslado al hospital no es posible de manera inmediata.

En el terreno militar, el elemento clave de la telemedicina es garantizar el asesoramiento experto en cualquier parte y en cualquier momento. En enero de 1995, la Advanced Research Projects Agency anunció el inicio del Advanced Biomedical Technology Program cuyo objetivo es la "telepresencia experta» en el campo de batalla que incluye, especialmente, el apoyo de diagnóstico médico por imagen. La extrapolación al campo aeroespacial es obvia. Un futuro más lejano contempla la posibilidad de colocar sensores no invasivos en localizaciones estratégicas en todo un edificio. Sensores de uso personal podrán, por ejemplo, detectar un cáncer de cólon; sensores de metabolitos de determinados fármacos en orina o en el sudor podrán asegurar un tratamiento correcto; microsensores de glucosa, de oxihemoglobina o de presión arterial/pulso, en el teléfono, podrán, al asirlo, informar al hospital. De igual modo, sensores ultrasónicos en la ducha podrán detectar lesiones mamarias.

"Hemos agotado la exéresis quirúrgica. El futuro de la cirugía se encaminará por el trasplante o por los órganos artificiales». Son palabras pronunciadas en el año 1957. Como el «hombre de hojalata» del Mago de $\mathrm{O} z$, miles de pacientes con enfermedades cardiacas, hígados enfermos o 


\section{Pedro García Barreno}

406

TABLA I. Biónica: un panorama histórico

\begin{tabular}{|c|c|c|}
\hline & prótesis & sangre, órganos, tejidos \\
\hline 1504 & Mano de hierro con dedos articulados. & \\
\hline 1597 & & Reconstrucción nasal con injertos tisulares. \\
\hline 1628 & & Teoría de la circulación de la sangre. \\
\hline 1666 & & Transfusión de sangre entre dos perros. \\
\hline 1667 & & Transfusión de sangre de oveja a humano. \\
\hline 1682 & & $\begin{array}{l}\text { Reparación de cráneo humano con hueso } \\
\text { craneal canino. }\end{array}$ \\
\hline 1822 & & Autoinjerto de piel. \\
\hline 1847 & Amalgama de plata en odontología. & \\
\hline 1881 & & Aloinjerto de piel. \\
\hline 1883 & & Solución Ringer para conservar tejidos. \\
\hline 1888 & Lente ocular de contacto & \\
\hline 1901 & & Grupos sanguíneos. \\
\hline 1905 & Prótesis artificial de cadera. & $\begin{array}{l}\text { Trasplante de cornea. } \\
\text { Cultivo celular in vitro. } \\
\text { Transfusión de sangre entre humanos. }\end{array}$ \\
\hline 1908 & Prótesis de rodilla de cadáver. & \\
\hline 1911 & $\begin{array}{l}\text { Inyección de parafina para tratar } \\
\text { parálisis de las cuerdas vocales. }\end{array}$ & \\
\hline 1914 & & $\begin{array}{l}\text { Citrato (anticoagulante) para almacenar } \\
\text { sangre. }\end{array}$ \\
\hline 1928 & Pulmón artificial para tratar polio. & \\
\hline 1943 & Riñón artificial. & \\
\hline 1949 & & $\begin{array}{l}\text { Implicación del sistema inmune en el } \\
\text { rechazo de injertos. }\end{array}$ \\
\hline 1951 & Implante válvula cardiaca artificial. & \\
\hline 1953 & Máquina corazón-pulmón. & \\
\hline 1954 & & Trasplante renal entre gemelos. \\
\hline 1956 & & Isotrasplante de médula ósea \\
\hline 1957 & Implante coclear. & \\
\hline 1958 & Marcapaso cardiaco implantable. & $\begin{array}{l}\text { Importancia del sistema de histo- } \\
\text { compatibilidad en el tipaje de tejidos. }\end{array}$ \\
\hline 1963 & & Trasplante hepático. \\
\hline 1966 & & Trasplante de páncreas. \\
\hline 1967 & & Trasplante cardiaco. \\
\hline 1969 & $\begin{array}{l}\text { Cerámica biocompatible. } \\
\text { Corazón artificial total. }\end{array}$ & \\
\hline 1972 & Prótesis de cadera acero/polímero. & \\
\hline 1973 & & Alotrasplante médula ósea. \\
\hline 1978 & & Ciclosporina. \\
\hline 1979 & Audioimplante en tronco cerebral. & \\
\hline 1981 & $\begin{array}{l}\text { Puente nervioso implantado en la } \\
\text { médula espinal lesionada de una rata. }\end{array}$ & \\
\hline $\begin{array}{l}1982 \\
1983\end{array}$ & Jarvik-?: primer corazón artificial total. & $\begin{array}{l}1^{\text {er }} \text { fármaco bioingenierizado (insulina). } \\
\text { Trasplante de pulmón. }\end{array}$ \\
\hline 1984 & & $\begin{array}{l}\text { Baby Fae recibe el corazón de un } \\
\text { babuino, sobreviviendo } 20 \text { días. }\end{array}$ \\
\hline 1987 & Hígado bioartificial. & \\
\hline 1990 & & FK506: nuevo fármaco inmunodepresor. \\
\hline 1993 & $\begin{array}{l}\text { FDA aprueba la asistencia mecánica } \\
\text { ventricular izquierda como un puente } \\
\text { hacia el trasplante cardiaco. }\end{array}$ & \\
\hline 1995 & & $\begin{array}{l}\text { Xenotrasplante de médula ósea de un } \\
\text { babuino. }\end{array}$ \\
\hline 1997 & & $\begin{array}{l}\text { Trasplante de neuronas porcinas en } \\
\text { pacientes con Enf. de Parkinson. }\end{array}$ \\
\hline 1998 & & $\begin{array}{l}\text { Trasplante de una mano humana. } \\
\text { Trasplante total de laringe. }\end{array}$ \\
\hline 2000 & Implante de un páncreas artificial. & \\
\hline 2001 & Implante de AbioCor ${ }^{\star}$. Bion ${ }^{\infty}$. Dextra ${ }^{\infty}$. & \\
\hline
\end{tabular}


tejidos lesionados, necesitan -para seguir joviales y alegres- conseguir un órgano para reemplazar el suyo caduco. Acuciados por la escasez de órganos disponibles para trasplantar, bioingenieros, biólogos celulares y clínicos, han unido sus habilidades para diseñar repuestos de cualquier parte del cuerpo humano. Un sueño que no es nuevo (Tabla I).

La biónica - en el contexto médico, este término se refiere al desarrollo de órganos artificiales (desde una prótesis ocular a una retina artificial; desde un corazón artificial a un marcapaso cardiaco; etc). También se refiere a artilugios mecánicos que emulan el comportamiento de un organismo vivo (desde un miembro artificial controlado electromecánicamente a robots de diferentes tipos) - tiene una rica y fascinante historia. Tal vez, en el contexto biónico, uno de los temas más conocidos es el del corazón artificial. El renovado interés de los medios de comunicación por el corazón artificial total. Los trasplantes de corazón se contemplan como milagros por su impacto en la cuantía y calidad de vida; desafortunadamente, como los milagros, no se prodigan. Cada año, en los EE.UU., alrededor de 2000 pacientes con fracaso cardiaco terminal reciben un corazón ajeno. Y otros 400000 individuos desarrollan fracaso cardiaco cada año; de ellos, 30000 a 100000 son candidatos potenciales a un trasplante cardiaco. Los médicos -arropados por un consenso general-deben determinar, entre todos ellos, cuales son los candidatos para un trasplante. La edad, otras enfermedades concomitantes o determinados hábitos, son condicionantes desfavorables. Pero nadie quiere encontrarse en la incómoda posición de tener que decidir quién accede y quién no. Así, los médicos, durante décadas, han desarrollado, de la mano de ingenieros y otros especialistas, máquinas complejas -marcapasos y válvulas artificiales cardiacas- que pueden salvar pacientes terminales. El objetivo final es desarrollar una máquina tan buena o incluso mejor, que el corazón donado evitando la necesidad de un trasplante. Como resultado del amplio eco en los medios de comunicación de la reintroducción del corazón artificial total (total artificial heart, TAH) en julio de 2001, el interés de la comunidad médica y de los ciudadanos en general ha reabierto la discusión sobre la utilización de los sistemas mecánicos de asistencia circulatoria en el tratamiento de las cardiopatías terminales. Un implante TAH es una intervención de alto riesgo que reemplaza la función cardiaca que pasa a depender de la tecnología más sofisticada de las aplicadas hasta ahora en el ser humano. Un TAH debe latir, aproximadamente, entre 35 y $40 \mathrm{mi}$ llones de veces por año, asegurando una eyección de sangre por el corazón entre 5 y 6 litros por minuto. Los diseños actuales ofrecen una fiabilidad del $90 \%$ tras cinco años de su implante, que es comparable a un $70 \%$ de supervivencia para los trasplantes cardiacos hoy día. El TAH AbioCor es 
una construcción de titanio y polímeros que utiliza un sistema electrohidráulico para cortacircuitar la sangre de las cámaras de eyección derecha e izquierda del corazón. Un TAH presenta muchos retos de diseño. Con toda probabilidad el paciente morirá rápidamente si la máquina falla. El principal problema es la formación de coágulos sobre las válvulas de la prótesis como respuesta al contacto del material «extraño» con el que la sangre está constantemente en contacto, y facilitado por las condiciones hidrodinámicas del flujo sanguíneo provocadas por el perfil interno de la prótesis. También pueden surgir problemas pulmonares por falta de acoplamiento entre los flujos derecho e izquierdo de la prótesis. La infección es otra amenaza. Problemas de diseño hacen que los TAHs no se adapten a los tórax de mueres y niños.Las limitaciones inherentes de la tecnología TAH actual hacen que sólo el $10 \%$ de los pacientes con cardiopatía terminal sean candidatos a tal estrategia terapéutica. Frente a ello, la mayoría de los clínicos creen que el $90 \%$ de tales pacientes pueden beneficiarse de asistencia mecánica ventricular (ventricular assist device, VAD) que ayuda al ventrículo izquierdo, la localización preferente del daño cardiaco grave. Durante el reposo ventricular que asegura el VAD, el músculo cardiaco enfermo comienza su recuperaçión pudiendo conseguir la reparación y mejorar la función eliminado a veces, incluso, la necesidad de un trasplante posterior. El diseño de los VADs comenzó a principios de los 1960s, pero su progreso se aceleró significativamente en los 1990s. Hasta la fecha miles de pacientes se han beneficiado, a veces durante varios años, de los VADs. El más utilizado es el HeartMate, un motor que produce un flujo de sangre pulsátil y al que se asigna una incidencia de émbolos de un $2 \%$ utilizando exclusivamente aspirina como anticoagulante. Más recientemente se han desarrollado bombas -más sencillas y baratas- que producen un flujo de sangre continuo no pulsátil, que no provoca pulso palpable ni presión sanguínea periférica medible. Los prototipos de este último sistema VAD incluyen el Jarvik 2000, Micro-Med DeBakey y HeartMate II, todos en fase de ensayo clínico.

Otro frente lo representa la tecnología capacitante, que puede transformar la vida de un gran número de individuos con minusvalías. Los ingenieros biónicos se esfuerzan en construir herramientas que restablezcan la movilidad en aquellas personas que han perdido, física o funcionalmente, una de sus extremidades. Esas herramientas son el resultado de la amalgama de los materiales más avanzados, de microelectrónica y megacomputación, de robótica avanzada y de sofisticados algoritmos. Esos ingenieros están aprendiendo cómo y donde pueden acceder al sistema sensorimotor residual a efectos de transmitir sus «intentos» a las partes corporales reemplazadas o reactivadas. 
Cuando se reemplaza una parte corporal perdida por otra artificial aparece un ingrediente de lo más común: la comunicación. Desafortunadamente, para las partes biónicas, la comunicación es el eslabón más débil de la cadena de componentes que incluye electrónica, computación, actuadores (actuators), mecanismos y materiales. La profunda brecha entre las capacidades humanas y de las máquinas es reflejo de esa falta de comunicación. La biónica puede restaurar la motilidad perdida si el paciente, primero, puede expresar control cognitivo sobre funciones motoras relevantes a través de una anatomía residual, y, segundo, si un diseño electrónico puede recoger y descifrar esa voluntad. El primer requerimiento queda satisfecho en aquellos individuos que han perdido alguna función por parálisis o por amputación, pero que pueden imaginar que controlan articulaciones afuncionales o ausentes. Esos individuos expresan control motor sobre sus miembros perdidos mediante una actividad neuromuscular dirigida a sus miembros residuales; una expresión que puede registrarse mediante la apropiada tecnología. Pacientes que no reúnen este requisito por lesión del componente neuromuscular residual tienen una opción quirúrgica reconduciendo sus nervios motores de la mano a regiones alternativas. Por ejemplo, transferir las señales de control de una mano hacia los músculos pectorales, donde puede ser fácilmente accesible y descifrada.

El segundo requerimiento es más problemático dada la complejidad del control del movimiento humano. Cada acción se origina a partir de unas pocas neuronas de la corteza frontal, cuyo trabajo conjunto dispara la actividad de un complejo entramado neuronal que coordina las acciones de varios músculos agonistas efectores tras recibir y procesar información de retroalimentación a partir de millones de sensores táctiles, posicionales y visuales. Ello constituye una nueva disciplina: háptica. Transformar esa maraña de millones de pulsos eléctricos en movimientos gráciles es una rutina ejecutada sin dificultad por el sistema sensomotor, pero que la ingeniería biónica apenas comienza a vislumbrar. Sin embargo, el primer paso ya está dado con el RoboWalker(B), un exoesqueleto que posibilita andar a individuos paralíticos.

Aunque difícil de duplicar, el sistema sensomotor humano está siendo abordado por interfaces biónicas cada vez más versátiles (Tabla II). El control cognitivo de miembros artificiales, al menos para funciones primitivas como agarrar, puede conseguirse con una interfaz cerebro-máquina biónica (brain-machine interface, BMI) en individuos con miembros amputados o paralíticos. Pacientes con discapacidades motoras pueden desarrollar habilidades primarias cuando las instrucciones de sus cerebros o médulas espinales son recogidas mediante métodos no in- 
vasivos (electroencefalograma, EEG) o por medio de electrodos implantados. Pacientes tetrapléjicos entrenados con un chip implantado en el cerebro han aprendido a mover cursores y seleccionar letras en una computadora, y a dirigir los movimientos de un brazo robótico utilizando una tecnología conocida como interfaz cerebro-computadora (brain-computer interface, $\mathrm{BCI}$ ).

¿Cuántas más funciones pueden restaurarse con sistemas biónicos avanzados? Funciones complejas - andar- probablemente no puedan conseguirse a partir de métodos no invasivos -EEG- por su pobre resolución de la actividad cerebral. La dificultad de extraer información volitiva del EEG se debe a las limitaciones de la tecnología actual, incapaz de descifrar más de 25 bits de información (tres caracteres) por minuto. El movimiento más simple exige una velocidad de procesamiento miles de veces más rápida. Una resolución más fina y por ello más funcional, puede obtenerse mediante el registro directo a través de electrodos implantados en la corteza cerebral. El mínimo número de neuronas requeridas para elaborar un conjunto de movientos coordinados excede, probablemente, las mil; sin embargo, la electrónica hoy disponible para disponer de mil canales es demasiado voluminosa para adaptarla al cráneo humano. Por ahora, electrónica del tipo BCI o BMI debe ubicarse sobre la superficie craneal y recibir; una tecnología que, en primates, ha demostrado su operatividad en tiempo real.

Mientras que las interfaces cerebrales bucean en el sistema sesomotor, poniendo directamente al cerebro al frente del control del movimiento, estrategias biónicas alternativas circuitean al cerebro y se co-

TABLA II. Estrategias para la restauración biónica del movimiento

\begin{tabular}{|lll|}
\hline $\begin{array}{l}\text { Estrategia biónica } \\
\text { (electrodos externos } \\
\text { o implantados) }\end{array}$ & Usuarios potenciales & Tipos de actuadores \\
\hline BMI (brain-machine interface) & $\begin{array}{l}\text { Personas tetrapléjicas que pueden } \\
\text { beneficiarse de diseños mecánicos. }\end{array}$ & $\begin{array}{l}\text { Motores (por ej, mover } \\
\text { brazos robóticos). }\end{array}$ \\
BCI (brain-computer interface) & $\begin{array}{l}\text { Personas tetrapléjicas que desean, } \\
\text { simplemente, comunicarse. }\end{array}$ & $\begin{array}{l}\text { Computadoras (por ej., } \\
\text { mover un cursor). }\end{array}$ \\
PMI (peripheral-machine interface) & $\begin{array}{l}\text { Amputados y pacientes con SNC } \\
\text { intacto pero miopáticos. }\end{array}$ & $\begin{array}{l}\text { Motores (por ej., mano } \\
\text { protésica). }\end{array}$ \\
HBMI (hybrid brain-machine interface) & $\begin{array}{l}\text { Lesión medular con músculos } \\
\text { intactos. }\end{array}$ & $\begin{array}{l}\text { Músculos (por ej., control } \\
\text { cerebral directo de FreeHand). }\end{array}$ \\
CBI ( computer-brain interface) & Enfermedad de Parkinson. & Músculos. \\
\hline
\end{tabular}


munican directamente con el sistema neuromuscular periférico. Tales interfaces periferia-máquina (PMI) operan mediante estimulación eléctrica funcional (FES) de los nervios y músculos periféricos y que pueden programarse para patrones o conjuntos de movimientos específicos. Un ejemplo es FreeHand, el primer brazo biónico aprobado por la Food and Drug Administration. FreeHand restaura la capacidad de agarrar en pacientes con parálisis de los miembros superiores; ello mediante el control, sobre los músculos extrínsecos de la mano, por los músculos del hombro que generan ondas de radio que activan electrodos en el antebrazo.

Las tecnologías biónicas pueden adaptarse para restaurar, en algún grado, casi cualquier función perdida. Hoy, el interés se orienta, principalmente, hacia los paraplégicos quienes pueden deambular mediante diseños tipo exoesqueletos y, sin ayuda externa, mediante la estimulación programada de la médula espinal. La estrategia estrictamente periférica requiere tecnología FES que microcontrole todas las acciones. Un control más natural puede conseguirse mediante el desarrollo de interfaces híbridas cerebro-máquina (hybrid brain-machine interfaces, HBMIs), en las que las señales volitivas recogidas electoencefalo-gráficamente pueden controlar los músculos.

Un nuevo diseño - Bion- ha supuesto un destacado avance en la coordinación biónica de los movimientos musculares. Biones son estimuladores del tamaño de un grano de arroz que pueden inyectarse en los músculos con una aguja estándar y controlarse por una fuente externa de radiofrecuencia. Diferentes ensayos clínicos han demostrado su operatividad durante más de un año. Diversos biones pueden controlar, de manera independiente, cada uno de los músculos involucrados en un movimiento coordinado. El control directo de los músculos es deseable porque, al contrario de los actuadores robóticos, los músculos humanos responden, incomprensiblemente, de un modo no lineal e impredecible a su controlador natural, las neuronas.

Cuando se excluye al cerebro de los circuitos de control, los ingenieros biónicos deben descodificar, de alguna manera, la volición en la periferia. La estrategia más común para entrenar a los usuarios a ejecutar actividades musculares específicas para producir patrones electromiográficos (EMG) superficiales, reconocibles por el descodificador. Esta estrategia puede restaurar un número limitado de actividades, como agarrar en una dimensión; pero es incapaz de resolver voliciones con más de un grado de libertad. Otra alternativa de control EMG registra voliciones en el conjunto tridimensional de fuerzas generadas en el miembro residual: imagen cinética residual (residual kinetic imaging, RKI). Una ven- 
taja del RKI es que es biomimético: las vías motoras originales pueden utilizarse para controlar partes robóticas sustitutivas, como los dedos de una mano; ello lo consigue la prótesis manual biomimética Dextra. Cada estrategia de restauración biónica se especializa para su utilización en una situación característica, particular. Por ejemplo, BCI (interfaz cerebro-computadora) está indicada en pacientes con parálisis extensas, para quienes la comunicación más simple con el mundo externo es el objetivo primario. La estrategia especular de BCI, CBI (interfaz computadora-cerebro), puede tratar condiciones como la enfermedad de Parkinson, dominada por los temblores. El primer diseño comercial con este propósito, Activa Tremor Control, estimula rítmicamente el tálamo para simular las operaciones de las neuronas enfermas.

Personas con un sistema nervioso central intacto que han perdido completamente la función de grupos musculares específicos pueden ser ayudados por diseños robóticos controlados directamente desde el cerebro mediante sistemas HBMI, o desde los músculos o los nervios periféricos a través de sistemas PMI. Artilugios estrictamente periféricos, como RoboWalker antes citado, pueden controlarse merced a la activación muscular. Tales interfaces, posiblemente en combinación con reinervación quirúrgica, puedan beneficiar a parapléjicos, amputados y a otras enfermedades neuromusculares. Es posible que los problemas de las interfaces vayan resolviéndose con rapidez; pero existen otras limitaciones. En primer lugar, la microtecnología no elimina el problema de la limitación de espacio; una interfaz mínima para abordar movimientos primarios exige una superficie de $60 \mathrm{~cm}^{2}$. Solo la nantotecnología solucionará el problema. Conseguida la miniaturización adecuada, otro problema es conseguir sellar herméticamente el mecanismo a efectos de aislarlo de la corrosión insalvable de los fluidos orgánicos. Tampoco debe olvidarse la susceptibilidad de la electrónica, en especial de los sistemas digitales, a la interferencia electromagnética. Los requerimientos energéticos y de computación, en especial los sistemas de descodificación, son otros retos sin resolver. Por último, y a efectos de conseguir un control por retroalimentación, el enraizamiento de la prótesis -osteointegración- es un tema relevante; ello proporcionará un engarce sensorial que es crucial para la restauración biónica de la función.

En el año 2003, Kevin Warwick, profesor de cibernética de la Universidad de Reading (U.K.), se convirtió en el primer ciborg real. Conectó los dos extremos de los nervios seccionados de uno de sus brazos a una colección de microprocesadores; una computadora analizó y clasificó diferentes patrones de actividad. Las señales nerviosas centrífugas y centrípetas fueron interpretadas por la computadora, que envió centrí- 
peta y centrífugamente, respectivamente, las señales requeridas. Warwick hizo lo mismo en uno de los brazos de su esposa, realizando una comunicación biónica, entre ambos, motora y sensorial. La polémica está servida; excitante para unos, amoral para otros.

En tercer lugar, esta alianza microtecnológica tiene, también, una vertiente diagnóstica. Un biosensor es un dispositivo analítico que incorpora un sensor orgánico que traduce los parámetros químicos de un sistema en una señal óptica o eléctrica. Los biosensores tienen aplicaciones en estudios ambientales, alimentarios, agrícolas, militares y médicos. Aunque aún en desarrollo, prometen el estudio preciso y fiable de metabolitos específicos, fármacos y drogas y otras moléculas de importancia en los campos referidos. Los biosensores han mostrado su primera aplicación real en medicina. En unos sistemas sanitarios en revisión, la monitorización del paciente en su propio domicilio y por él mismo tendrá, cada vez, mayor auge; ello permitirá la detección precoz de cambios bioquímicos que determinarán la actuación inmediata del médico (diabetes, embarazo, administración de anticoagulantes, etc.). En el mismo sentido, la utilización de biosensores en la consulta médica extrahospitalaria acabará imponiéndose a los laboratorios hospitalarios de referencia; así, un minisistema compacto, construido por la NASA para su utilización en las estaciones espaciales, realiza diez determinaciones analíticas en unos pocos segundos, a partir de una gota de sangre. Existen técnicas que realizan determinaciones complejas a partir de $0.01 \mathrm{ml}$ y de $10 \mathrm{mg}$ de muestra. También, el desarrollo de mini y microsistemas de administración continua de fármacos exige el desarrollo paralelo de sensores de larga duración conectados a un sistema de retroalimentación que regule la administración del fármaco. En la actualidad, se dispone de la tecnología necesaria para detectar más de cien compuestos de interés biológico; capacidad analítica que se ofrece en diferentes combinaciones orientadas a otras tantas patologías (perfiles diabetológicos, hepatológicos, nefrológicos, etc.).

La ¿última? frontera. Si se desintegra un cuerpo humano en sus ingredientes más básicos se obtendrán unos pequeños tanques de oxígeno, de hidrógeno y de nitrógeno. Unos montoncitos de carbono, de calcio y de diferentes sales. Unas pizcas de azufre, fósforo, hierro y magnesio y trazas de otros veinte, más o menos, elementos. Valor en el mercado: no mucho. Desde el punto de vista de lo que los científicos llaman nanoingeniería, la naturaleza manipula tan baratos, abundantes e inanes ingredientes en criaturas autoconscientes que se autoperpetúan, autogeneran y autorreparan; que caminan, sienten, piensan y sueñan. Valor total: incalculable. La aplicación humana de la nanotecnología co- 
mienza a emerger. La pregunta es: ¿qué podrán hacer los humanos si llegan a ser capaces de ensamblar los componentes básicos de la materia con el mismo virtuosismo que ha logrado la naturaleza? ¿de qué scrán capaces si logran rehacer el mundo átomo a átomo, molécula a molécula? Los más entendidos suponen que la nanociencia y la nanotecnología transformarán la sociedad cuando sean capaces, que lo serán, de controlar el agua, la electricidad, los antibióticos, la célula o la microelectrónica.

En abril de 1998, Neal Lane, Asesor del Presidente de los EE.UU. para Ciencia y Tecnología y que con anterioridad había sido el director de la Fundación Nacional para la Ciencia, explicitó ante el Congreso de su país que «si se le preguntaba por un área de la ciencia y de la ingeniería responsable de drásticas innovaciones en el futuro, señalaría sin dudar a la ciencia y a la ingeniería nanoescalares llamadas, simplemente, nanotecnología». Son ahora numerosos, entre ellos, el Premio Nobel de Física de 1998 Horst Störmer -lo compartió con Robert Laughlin y Daniel Tsui por sus estudios del efecto cuántico fraccional de Hall-, quienes están convencidos de que la emergente nanotecnología permitirá a la humanidad un control sin precedentes del mundo material. Richard Smalley señala que la nanotecnología es la última frontera de la manipulación de la materia. La posibilidad de fabricar nuevas cosas parece no tener límite alguno. ¿Qué entienden los científicos como Lane, Störmer o Smalley por nanotecnología? En el lenguaje de la ciencia, el prefijo nano significa la milmillonésima parte de algo: de un metro, de un segundo. La nanociencia y la nanotecnología se refieren a un mundo de dimensiones nanométricas; entre 1 y 200 nanometros $\left(1-200 \times 10^{-9} \mathrm{~m}\right)$; el contexto espacial natural de las moléculas y sus interacciones. Los jugadores en esta dimensión se distribuyen en un amplio abanico de estructuras, desde la molécula triatómica del agua a moléculas mucho mayores como la hemoglobina formada por miles de átomos, y la gigantesca molécula de ADN con millones de átomos (Figura 12).

Un nanómetro, la milmillonésima parte de un metro, es la esencia de lo minúsculo. Un nanómetro es, también, la dimensión en la que opera una nueva rama de la tecnología. "Me gustaría abordar un campo en el que se ha hecho poco pero en el que, en principio, puede hacerse una enormidad « comentaba Richard Feynman (1918-1988; compartió el Premio Nobel de Física con Sin-Itiro Tomonaga (1906-1979) y Julian Schwinger (1918-1994) «por su trabajo fundamental en electrodinámica cuántica, con profundas repercusiones para la física de las partículas elementales») en su, ahora clásica, conferencia There's Plenty of Room at the Botton, dictada el 29 de diciembre de 1959 durante la reunión anual de la Sociedad 

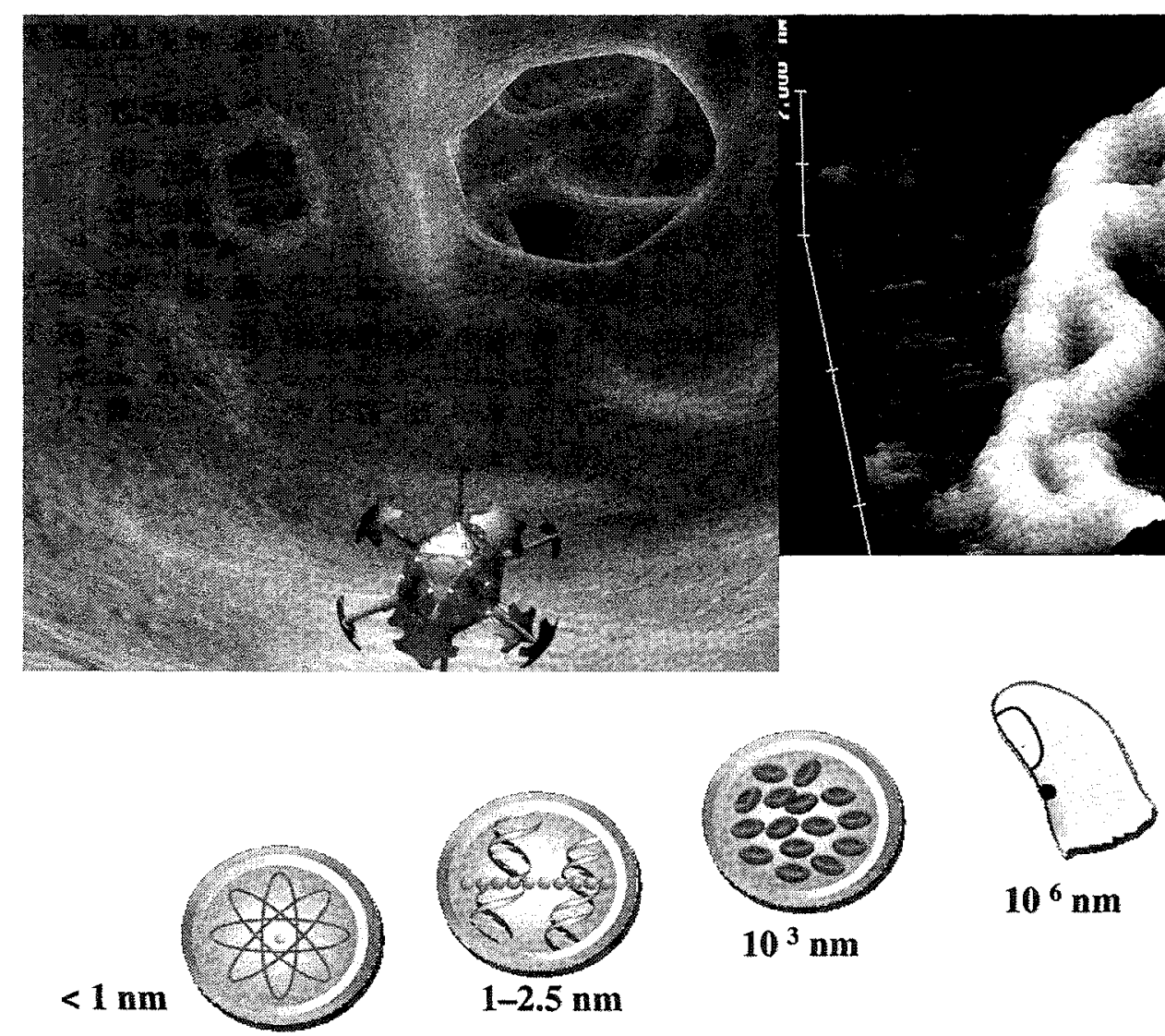

$10^{6} \mathrm{~nm}$

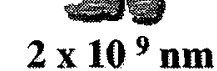

FIGURA 12. La nanotecnología aborda el mundo de lo minúsculo. Los nanodocs explorarán el interior del cuerpo utilizando los mismos sistemas de navegación que los que permiten a los submarinos atómicos recorrer los océanos sumergidos durante meses, y utilizarán minúsculas herramientas para reparar, directamente, las estructuras subcelulares.

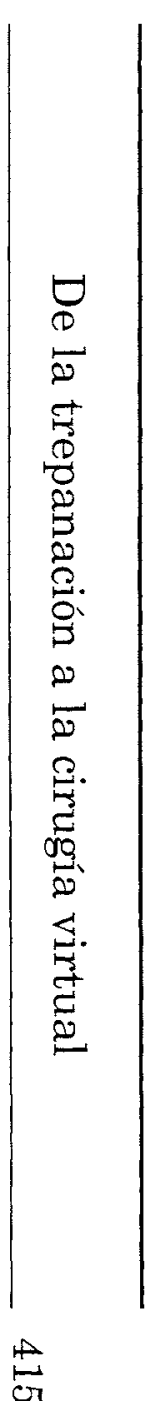


Americana de Física - ... Lo que quiero es hablar sobre el problema de manipular y controlar la materia a una escala minima. Cuando lo comento me responden hablando de miniaturización; de motores eléctricos del tamaño de una uña o de dispositivos con los que se puede escribir el Padre Nuestro en la cabeza de un alfiler. Pero mi idea no tiene que ver con esto, aunque representa el primer paso en la dirección de lo que quiero discutir: el asombroso y minúsculo mundo subyacente. En el año 2000, cuando hagan balance de nuestro siglo, se sorprenderán de que no fuera hasta el año 1960 cuando alguien comenzó a moverse, seriamente, en tal dirección. ... Ofrezco -comunicó Feynman- un premio de $\$ 1000$ al primero que pueda reducir en una escala lineal de $1 / 25000$ la información contenida en la página de un libro, de tal manera que pueda ser leida por un microscopio electrónico. Y quiero ofrecer otro premio de otros $\$ 1000$ a quién construya un motor eléctrico rotatorio, con control externo, con las dimensiones de un cubo de 1/64 pulgada». A Feynman le cautivó la biología: «Un sistema biológico puede ser algo mínimo. Los organismos unicelulares son criaturas autosuficientes de tamaño extraordinariamente pequeño: son activos, manufacturan diferentes componentes, se mueven, almacenan información y hacen toda clase de cosas maravillosas a una escala muy pequeña».

En este mundo de lo minúsculo, el compromiso de la nanociencia con la medicina vislumbra varios desafíos; uno de ellos es desarrollar capacidades que permitan manipular células o grupos celulares utilizando nanoobjetos fabricados que sean capaces de interactuar o reemplazar estructuras funcionales determinadas. El típico nanodispositivo médico «nanodoc» - será un robot de escala micrométrica formado por el ensamblaje de partes nanoescalares; componentes de 1-100 nm que formarán una micromáquina de $0.5-3 \mu \mathrm{m}(10-6 \mathrm{~m})$. Los nanodocs más estudiados hasta la fecha son los respirocitos o mecanoeritrocitos artificiales, los plaquetocitos, «clotocitos» o mecanoplaquetas y las microvíboras o mecanofagocitos. No se escapa la posibilidad de construir microherramientas capaces de operar a nivel subcelular.

La medicina está sometida a cambios que recuerdan lo acontecido con la Revolución Industrial. La tendencia de la cirugía de evadir la incorporación de nueva tecnología debe cambiar; la cirugía de invasión mínima abre las puertas del futuro de la mano de la imagen intervencionista y la telemedicina y, ya en puertas, de la nano y microtecnologías, y algo más allá, la cirugía virtual. Todo ello sobre la base de un impresionante avance en las bases científicas. En cualquier caso, desde el punto de vista de la cirugía clínica, la ciencia y la práctica médicas sólo han experimentado un modesto desplazamiento desde un arte u oficio hacia una disciplina más racional y con una sólida base científica. Debemos poner nuestras 
De la trepanación a la cirugía virtual

esperanzas en mejor y más ciencia; pero la enfermedad es un problema biológico enormemente complejo que debe ser comprendido a muy diferentes niveles: desde las moléculas -medicina molecular - hasta las comunidades -epidemiología. "Mientras haya enfermos que tratar -remacha David Weatheral, Regius Professor de Medicina de la Universidad de Oxford- la medicina, probablemente, seguirá teniendo mucho de arte».
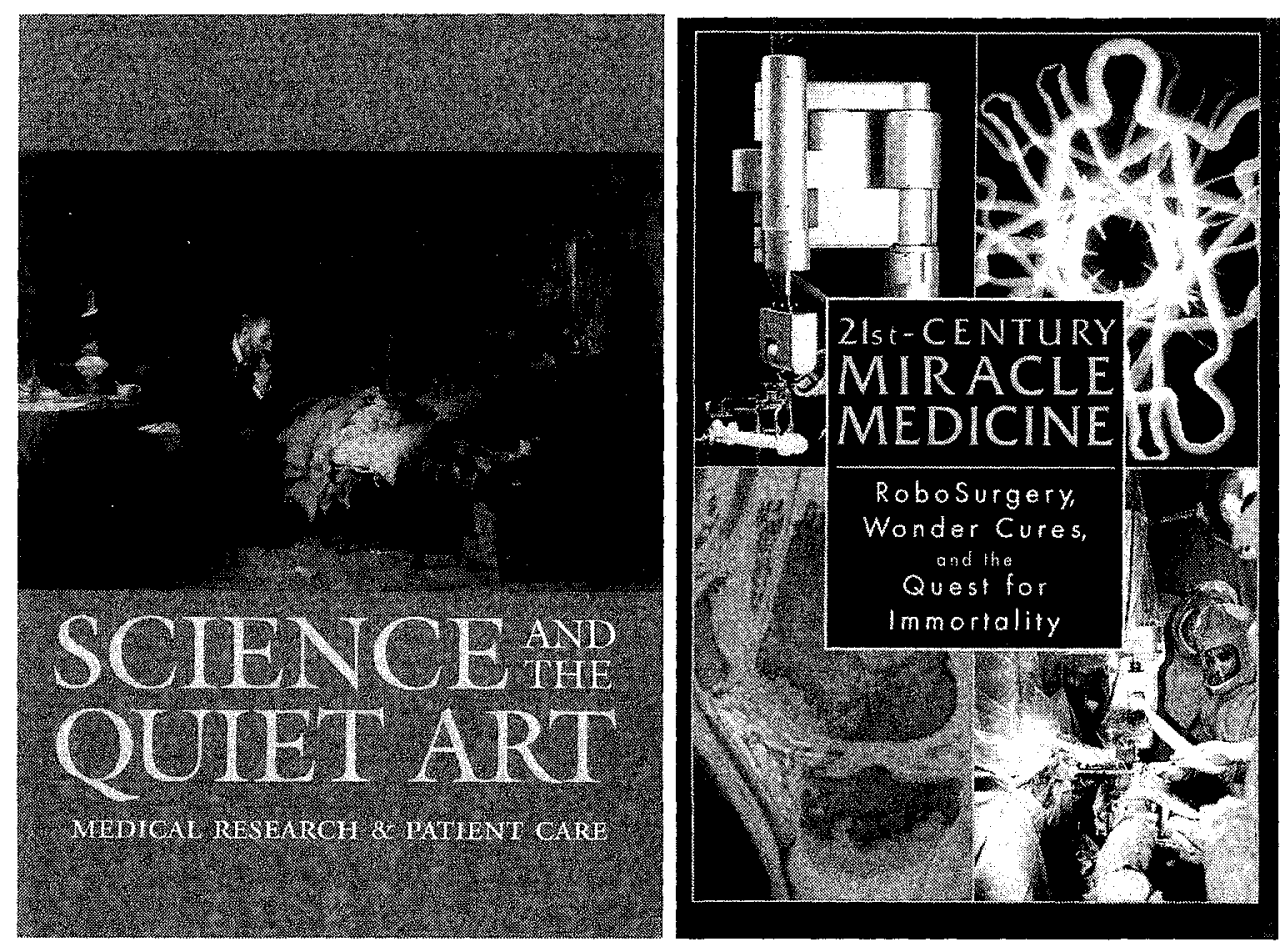